University of Louisville

ThinkIR: The University of Louisville's Institutional Repository

Electronic Theses and Dissertations

$12-2013$

\title{
Peptide mediated inhibition of Porphyromonas gingivalis dual and three species biofilms.
}

Naga Srinija Gummadi

University of Louisville

Follow this and additional works at: https://ir.library.louisville.edu/etd

\section{Recommended Citation}

Gummadi, Naga Srinija, "Peptide mediated inhibition of Porphyromonas gingivalis dual and three species biofilms." (2013). Electronic Theses and Dissertations. Paper 545.

https://doi.org/10.18297/etd/545

This Master's Thesis is brought to you for free and open access by ThinkIR: The University of Louisville's Institutional Repository. It has been accepted for inclusion in Electronic Theses and Dissertations by an authorized administrator of ThinkIR: The University of Louisville's Institutional Repository. This title appears here courtesy of the author, who has retained all other copyrights. For more information, please contact thinkir@louisville.edu. 
PEPTIDE MEDIATED INHIBITION OF PORPHYROMONAS GINGIVALIS DUAL AND THREE SPECIES BIOFILMS

\author{
By: \\ Naga Srinija Gummadi \\ University of Louisville School of Dentistry
}

\begin{abstract}
A Thesis Submitted to the Faculty
Of the School of Dentistry of the University of Louisville in

Partial Fulfillment of the Requirements for the Degree of
\end{abstract}

Master of Science

\author{
Oral Biology \\ School of Dentistry \\ University of Louisville \\ Louisville, KY
}

December 2013 
Copyright by Naga Srinija Gummadi in 2013

All Rights Reserved 

PEPTIDE MEDIATED INHIBITION OF PORPHYROMONAS GINGIVALIS DUAL AND THREE SPECIES BIOFILMS

\author{
By: \\ Naga Srinija Gummadi, \\ B.D.S., Dr. N.T.R University of Health Sciences, 2009
}

Thesis Approved on

November 27, 2013

By the following Thesis Committee

Dr. Donald R. Demuth, Ph.D.

Thesis Director

Dr. David A. Scott, Ph.D.

Dr. Jan S. Potempa, Ph.D. 


\section{DEDICATION}

I would like to dedicate this thesis first and foremost and specially to my God gifted Daddy Mr. Michael W. Lewellen without whom this would not have been possible. He helped me more than he can and perhaps worked more than me for this to come true. He is the most kind hearted person I have ever seen. Dad, you have strengthened me with your prayers, blessed me with your fatherly love and care and encouraged me with your hope. In short my daddy is- Friendly $\underline{\text { A}} w e s o m e ~ \underline{T}$ houghtful $\underline{\text { Heroic }} \underline{\text { Exceptional }} \underline{\text { Really }}$ a great person! I also like to dedicate this thesis to my God gifted Mom Mrs. Ruth A. Lewellen who encouraged me always and has been a great support to me in accomplishing my goal. Being a Role Model is the most powerful form of educating. Mom, you are beautiful, intelligent and you have good moral values- you are my best Role Model. My American parents are a true blessing to me from The Lord Almighty God. I am and will forever be grateful to have them as my parents. Family is not always blood relation. It's the people in your life who want you in theirs the ones who accept you for who you are. The ones who would do anything to see you smile and Love you no matter what. Thank you Mom and Dad. $\underline{\text { Father }} \underline{\text { And }} \underline{\text { Mother }} \underline{\mathbf{I}} \underline{\mathbf{L}}$ ove $\underline{\text { You. }}$

I also want to dedicate this to my Daddy Mr. G. Ram Babu who passed away 7years back. I didn't realize his importance when he was living and I miss him a lot. The values he instilled are ever present today. I also wish to dedicate this thesis to my Mom Mrs. G. Sridevi, my Aunt Mrs. Gadipathi Manjula Devi and my maternal grandparents Mr. Yalamanchili Narayana Rao and Mrs. Yalamanchili Yashoda Devi. 


\section{ACKNOWLEDGEMENTS}

First and foremost I want to thank The Almighty GOD, the compassionate, the almighty Merciful for both realized and unrealized blessings that he showered on me.

I'm extremely thankful to Dr. Donald R. Demuth for all his support, guidance and for giving me the hope and encouragement to finish my Masters. You are a wonderful mentor with tremendous expertise and knowledge and you have always been generous in sharing your valuable and rich knowledge in the field of research. You are a true inspiration to me. I can never forget the patience that you showed when I was not able to attend the lab, the encouragement that you gave every single time when I needed it, the support that you rendered when I faced adversity, and the faith you had in me all the while. I very much appreciate it and will be grateful to you always. You taught me to critically think and with your depth of knowledge and expertise you made research interesting. Thank you for giving me an opportunity to work in your lab. Your dedication and generosity with your time in helping me in the project is greatly appreciated. Thanking you is the hardest thing I have ever done because there is no way words by itself can express my gratitude towards you for being a wonderful mentor. Thank you for everything. I'm blessed to work with you.

I would also like to thank Dr. David A. Scott for serving on my committee. Thank you for your encouragement and help. You were always friendly and supportive. I truly appreciate it. It has been a blessing to have known you. Best wishes Dr. Scott! 
I would also like to thank Dr. Jan S. Potempa for serving on my committee. Thank you for always answering my questions with patience. Thank you for being so kind, helpful and supportive to me. It has been a blessing to have known you. Best wishes Dr. Potempa!

I also wish to thank Mrs. Barbara Potempa. You are a very kind, encouraging, loving, caring and a wonderful friend. I will never forget the encouragement that you gave me whenever I needed it. Thank you for all your good wishes. You gave me the strength to persevere. Thank you for your kindness and friendship. You are a beautiful blessing in my life. Thank you for everything and especially for wiping my tears off and bringing back a smile on my face in my tough times. Thank you so much. Best wishes Mrs. Barbara! 


\section{ABSTRACT \\ PEPTIDE MEDIATED INHIBITION OF P. GINGIVALIS DUAL AND THREE SPECIES BIOFILMS \\ NAGA SRINIJA GUMMADI}

November 27, 2013

The colonization of Porphyromonas gingivalis is the key phase in transformation of bacterial biofilm from a commensal plaque to pathogenic form observed in periodontitis.

Objectives: The goals of this study are to establish optimum levels of Porphyromonas gingivalis, Streptococcus gordonii and Fusobacterium nucleatum to reproducibly generate dual and three species biofilms and examine inhibition of biofilm formation by BAR peptide and BAR analogs $\mathrm{C}_{1-24} \mathrm{R}_{1182} \mathrm{I}_{1185} \mathrm{BAR}, \mathrm{R}_{1182} \mathrm{I}_{1185} \mathrm{BAR}$ and $\mathrm{C}_{1-24} \mathrm{BAR}$. Methods: $S$. gordonii was grown in BHIY media; $P$. gingivalis and $F$. nucleatum were grown in TSBY and BHI media respectively supplemented with hemin and menadione. Labeled $S$. gordonii was adhered to a cover glass in wells of a culture plate for 18-24 hours and then labeled $P$. gingivalis or $P$. gingivalis and $F$. nucleatum were added. After incubating for 18-24 hours, the cover glass is fixed, mounted onto a slide glass and visualized by confocal laser scanning microscopy. Biofilm images were assembled and analyzed using Volocity software. Results: For establishing the optimum inocula for Streptococcus gordonii, Porphyromonas gingivalis and Fusobacterium nucleatum- biofilms were formed using cultures of optical densities $0.05,0.1,0.2,0.5,0.8,1.0$ and 2.0. Optimal conditions were found to use $S$. gordonii at O.D 0.8, P. gingivalis at O.D 0.1(for 2 species), 0.2(for 3species) and Fusobacterium nucleatum at O.D 2.0. After the conditions were established, $P$. gingivalis was incubated with BAR peptide or BAR peptide analogs $(0-50 \mu \mathrm{g} / \mathrm{ml})$ prior to addition to $S$. gordonii to assess inhibition of biofilm formation. BAR peptide and peptide analogs significantly inhibited the biofilms. Inhibition of dual species biofilms by $\mathrm{R}_{1182}$ $\mathrm{I}_{1185} \mathrm{BAR}$ is statistically greater $(\mathrm{P}<0.001)$ compared to parent BAR. Conclusion: Ideal conditions for biofilms were established. BAR peptide and peptide analogs significantly inhibited adherence of $P$. gingivalis in both dual and three species complex biofilms 


\section{TABLE OF CONTENTS}

\section{PAGE}

DEDICATION..............................................ii

ACKNOWLEDGEMENTS............................... iv

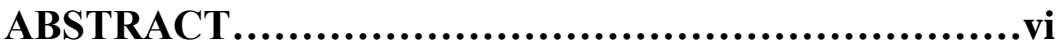

LIST OF FIGURES.......................................viii

CHAPTER 1: INTRODUCTION.............................1

CHAPTER2: HYPOTHESIS and AIMS................... 14

CHAPTER3: MATERIALS and METHODS.............. 17

CHAPTER4: RESULTS...................................... 31

CHAPTER5: DISCUSSION..............................67

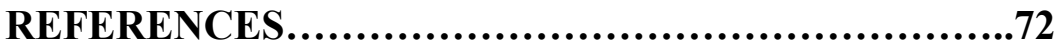

APPENDIX I: ABBREVIATIONS.........................78

CURRICULUM VITAE....................................79 


\section{LIST OF FIGURES}

FIGURE

PAGE

1. (A) - (D). Sequences of BAR peptide and its Analogs.................25

2. Various steps involved in three species biofilm formation...............30

3. Amino acids that promote or detrimental to $P$. gingivalis adherence to BAR peptide

4. (A) - (J) S. gordonii and P. gingivalis dual species biofilms at various optical densities

5. Efficiency of BAR peptide and its analogs at $10 \mu \mathrm{g} / \mathrm{ml}$.

6. Dose response of BAR peptide analogs in dual species biofilm.

7. (A) - (E) Dose response of $C_{1-24} R_{1182} I_{1185}$ BAR in dual species biofilm $45-46$

8. (A) - (E) Dose response of $\mathrm{R}_{1182} \mathrm{I}_{1185} \mathrm{BAR}$ in dual species biofilm......48-49

9. (A) - (E) Dose response of $\mathrm{C}_{1-24}$ BAR in dual species biofilm...........51-52

10. (A) - (C) Dose response of BAR peptide in three species biofilm..........56

11. (A) - (D) Dose response of $\mathrm{C}_{1-24} \mathrm{R}_{1182} \mathrm{I}_{1185} \mathrm{BAR}$ in three species biofilm....58

12. (A) - (D) Dose response of $\mathrm{R}_{1182} \mathrm{I}_{1185} \mathrm{BAR}$ in three species biofilm.......60

13. (A) - (D) Dose response of $\mathrm{C}_{1-24} \mathrm{BAR}$ in three species biofilm.............62

14. (A) - (B) Streptococcus gordonii and Fusobacterium nucleatum

dual species biofilm.......................................66 


\section{CHAPTER - 1}

\section{INTRODUCTION}

Periodontal disease is one of the most common oral disease among adults worldwide and remains as a major oral health care burden globally. Periodontal disease when left untreated can lead to chronic inflammation causing alveolar bone resorption and subsequent loss of teeth. According to the American Academy of Periodontology, periodontal disease is a chronic inflammatory disease that affects the gum tissue and bone supporting the teeth and data from the Centers for Disease Control and Prevention show high prevalence of periodontal disease in the U.S. population ${ }^{1}$. According to this study $50 \%$ of the American adult population at an age 30 and above exhibit some form of periodontitis ${ }^{1}$.

It's estimated that 47.2 percent of American adult population - nearly 64.7 million have mild, medium or severe periodontitis ${ }^{1}$. Severe periodontitis, which may result in tooth loss, is found in 5-20\% of most adult populations worldwide ${ }^{2,3}$. A study conducted by the Center for Disease Control and Prevention(CDC) demonstrated a high burden of periodontal disease in the adult United States population especially among age group 65 and older ${ }^{1}$.

Previous research studies have suggested that oral health might be indicative of overall general health ${ }^{4}$. These studies have also shown that periodontal disease was found to be 
associated with systemic conditions such as coronary artery disease, stroke, type 2 diabetes mellitus, severe osteopenia, pre-term or low birth weight babies and respiratory infections ${ }^{8_{2}}$ 4.

A frequent occurrence in chronic periodontitis is sub-gingival calculus ${ }^{5}$. An international workshop conducted in 1999 categorized a general guide for severity on the basis of clinical loss of attachment (CAL) as follows: slight or mild =1-2mm CAL; moderate $=3-4 \mathrm{~mm} \mathrm{CAL} ;$ severe $=5 \mathrm{~mm} \mathrm{CAL}^{6}$.

United States annual expenditure on periodontal and preventive periodontal procedures was $\$ 14.3$ billion in $1999^{7}$.

\section{Significance of Dental Plaque in Oral health and disease:}

The human oral cavity is similar to any other habitat present in the human body in hosting a variety of microflora. Among the microflora present in the oral cavity, bacteria are the most numerous and diverse group ${ }^{8}$ and are the primary etiologic agents in periodontal disease ${ }^{9}$.

Bacteria may be present either in free floating form or as being adhered to a surface

9. Bacterial attachment to a surface activates an entirely different set of genes in the bacterium resulting in imparting different characteristics to the bacterium which differ from those that it had as a free-floating organism ${ }^{9}$.

Previous research studies have shown that most of the bacteria exist in the form of biofilms which are characterized by highly organized densely populated bacterial 
communities embedded in an extracellular polymeric matrix ${ }^{9,10}$. A biofilm is mainly constituted by bacterial microcolonies, an extra cellular slime layer, fluid channels and a primitive communication system ${ }^{9}$. Each bacterial microcolony is a small independent group of bacteria comprising thousands of compatible bacteria ${ }^{9}$. During the biofilm formation the bacteria adhere to the surface and to each other thus forming clusters resulting in mushroom shaped bacterial micro colonies surrounded by an extracellular slime layer ${ }^{9}$. These mushroom shaped bacterial microcolonies are characterized by a narrow base that facilitates in there attachment to the surface ${ }^{9}$.

Each biofilm is distinct in composition with diverse combinations of a wide variety of oral bacteria present ${ }^{9}$. These diverse group of bacteria have different physiological needs and require different living conditions for their survival ${ }^{9}$. The biofilm structure is well organized that it serves the diverse needs of different bacterial microflora ${ }^{9}$. The bacteria present in the core of the bacterial microcolony survive under strict anaerobic environment while aerobic bacteria survive at the edges of fluid channels where aerobic environment prevails ${ }^{9}$. The extracellular slime layer provides protection to the bacterial microcolonies against antibiotics, antimicrobials, chemotherapeutic agents and host defense mechanisms ${ }^{9}$. A primitive communication system exists between the bacterial micro colonies in which they communicate with each other through chemical signals ${ }^{9}$. The fluid channels pass through the slimy extracellular matrix and provide nutrition and oxygen to the bacterial microcolonies ${ }^{9}$. In addition they also facilitate the movement of enzymes and metabolites throughout the biofilm and provide a system for elimination of bacterial waste products 9 
The bacteria present in the biofilms adhere to tooth surfaces, restorations, dental prosthetic appliances and on oral mucous membranes ${ }^{9,11}$.

\section{Development of dental plaque biofilm: Stages}

The growth and development of Dental plaque biofilm involves 4 phases: initial attachment phase, lag phase, rapid growth phase and steady state phase ${ }^{11}$.

\section{Phase 1 and 2: Initial attachment and Lag phase:}

The first phase involved in the dental plaque biofilm formation is the formation of the pellicle which is a thin layer of salivary proteins that includes albumin, glycoproteins, acidic protein-rich proteins, mucins, cell debris, and exo products such as amylase, lysozyme and sialic acid ${ }^{9,10}$. This pellicle coating forms on the tooth surface providing a sticky base on which colonization of specific bacteria occurs through specific interactions between bacterial surface components and salivary constituents ${ }^{11}$. The components of salivary pellicle including statherin, a salivary acidic phosphoprotein and proline-rich proteins promote the colonization of bacteria on to the tooth surfaces ${ }^{12}$. The early plaque forming bacteria or the initial colonizers are generally the gram positive cocci ${ }^{11}$. A phenotypic change occurs in the bacteria due to a shift of bacteria from planktonic life to a sessile life ${ }^{11}$. This needs a significant genetic up-regulation ${ }^{11}$. A lag in the bacterial growth occurs once the genetic expression shifts ${ }^{11}$.

\section{Phase 3: Rapid growth phase:}

During this phase biofilm matrix is formed from the secretions of the adherent bacteria. These secretions constitute large volumes of water-insoluble extracellular polysaccharides ${ }^{11}$. The bacterial microcolonies grow in this extracellular polymeric matrix 
11. Furthermore these early colonizing bacterial micro colonies get attached to various other new free floating bacteria and this results in both auto aggregation and co-aggregation

${ }^{9}$. This increases the bacterial complexity of the dental plaque biofilm ${ }^{11}$. Mutual support and competition among a highly diversified community of microorganisms occurs during the coaggregation of bacteria ${ }^{13}$. The process of coaggregation involves unique specific molecular interactions resulting in structural stratification within the biofilm ${ }^{10}$. The thickness of the biofilm increases as both coaggregation and cell division among the bacterial microflora progress ${ }^{14-16}$.

\section{Phase 4: Detachment phase or Steady state:}

During this phase disrupted bacterial cells and bacterial cells devoid of cytoplasm can be seen in the deeper layers of the biofilm while intact bacterial cells can be observed at the surface of the biofilms ${ }^{11}$. During this phase the interbacterial matrix might also exhibit crystals which may signify initial calculus mineralization ${ }^{17}$. In addition during this phase some of the bacteria detach from the biofilm surface sometimes as a reaction to harmful environmental conditions in relation to the bacteria ${ }^{11}$. These detached bacteria spread and colonize new surfaces in the oral cavity ${ }^{11}$.

The initially colonizing bacteria predominantly consists streptococcus species which are gram positive facultative cocci. In addition, the primary colonizers also constitute some gram positive rods and filaments and a few aerobic gram negative cocci ${ }^{9,10}$. The growth and development of the microbial biofilm is based on the cell division of the attached bacteria ${ }^{9}$. Further these bacteria form mushroom shaped bacterial microcolonies attached to the tooth surface ${ }^{9}$. Most of the oral bacterial microflora are characterized by multiple 
adhesion types on their cell surfaces which facilitate interactions with both the host surface molecules and other bacteria ${ }^{18}$.

Previous studies have shown that the healthy status of oral cavity is characterized by the predominant presence of gram positive cocci, some gram positive rods and filaments, few gram negative rods and a few gram negative cocci. The healthy status of the oral cavity changes to diseased status as the gram positive cocci and gram positive rods are replaced predominantly by pathogenic gram negative anaerobes or acidophiles ${ }^{9}$. After the plaque is predominantly composed of pathogenic bacteria, it results in the inflammation and swelling of the gingival margin which in turn results in deepening of the gingival sulcus ${ }^{9}$. The supra gingival plaque extends into the deepened gingival sulcus and gradually forms sub-gingival plaque biofilm which is mainly composed of gram negative anaerobic bacteria ${ }^{9}$.

Studies conducted by Socransky et. al ${ }^{19}$ have observed 5 consistent complexes of bacterial species of which the red complex containing Tanerella forsythus, Porphyromonas gingivalis and Treponema denticola has been significantly associated with clinical measures of periodontal disease, specifically pocket depth and bleeding on probing 19. Adult periodontitis is associated with sub-gingival plaque and is characterized by the predominant presence of $P$. gingivalis ${ }^{19}$. Porphyromonas gingivalis is found in the samples of dental plaque as early as within 6 hours after oral prophylaxis ${ }^{20,21}$. Oral prophylaxis is the complete removal of calculus, debris, stain and plaque and is performed by a trained specialist. P. gingivalis were found in greater amount in the areas affected with periodontitis ${ }^{22}$. The association of $P$. gingivalis with the initial, early, middle and late colonizers during biofilm growth may explain the presence of $P$. gingivalis as early as 
within 6hours after oral prophylaxis as well as its association with periodontal disease which is relatively a late event ${ }^{23}$.

Previous studies have shown that the colonization of $P$. gingivalis depends on various factors such as a "preformed streptococcal substratum" ${ }^{23}$, reduced oxygen tension and sufficient nutritional resources for it to get integrated into a biofilm ${ }^{24,25-27}$. Though streptococcal species constitute about $60-90 \%$ of the initial colonizers on the tooth surface, P. gingivalis does not exhibit biofilm formation with all the streptococcal species ${ }^{23}$. In fact P. gingivalis was observed to have "partner specificity ${ }^{23}$." For example $P$. gingivalis did not show biofilm formation with Streptococcus oralis ${ }^{28}$, Streptococcus mutans ${ }^{13}$ and Streptococcus cristatus ${ }^{29}$ whereas it effectively formed biofilms with S. gordonii ${ }^{13}$ and formed biofilms with $S$. oralis only in the presence of $S$. gordonii in a three species community $^{23}$. It did not readily form biofilms with $S$. mutans as there is a sequence variability between the antigens I/II proteins of $S$. mutans and S. gordonii which accounted for the binding selectivity of $P$. gingivalis ${ }^{30}$. In addition $P$. gingivalis did not exhibit coaggregation with some varieties of oral bacterial microflora like antinomies, aggregatibacteria, capnocytophagae, streptococcus ${ }^{28}$ whereas it exhibited co-aggregation with Fusobacterium nucleatum ${ }^{(23,28,31)}$. "P. gingivalis is capable of being an integral component of mutualistic multispecies oral biofilm communities at all stages of dental plaque development. ${ }^{21}$,

\section{Significance of Porphyromonas gingivalis and Fusobacterium nucleatum interaction in biofilm formation:}

Fusobacterium nucleatum also plays an important role in dental plaque biofilm formation due to its ability to colonize both with gram positive and gram negative bacteria in the oral cavity ${ }^{32}$. In fact $F$. nucleatum is also considered to be "microbial bridge" due 
to its co-aggregation ability ${ }^{33}$. It is found in high frequency in periodontal lesions ${ }^{57}$. Fusobacterium nucleatum adheres to the early colonizers including Gram positive cocci and then later facilitates the co-aggregation with strong periodontal pathogenic bacteria like $P$. gingivalis ${ }^{33}$.

Research studies showed that biofilm formation by $F$. nucleatum was significantly increased by the presence of $P$. gingivalis ${ }^{34}$. Both $P$. gingivalis and $F$. nucleatum were detected in the lesion areas associated with periodontitis ${ }^{35}$.

The synergistic effect between $P$. gingivalis and $F$. nucleatum was comparatively the strongest when compared to other oral bacterial micro flora ${ }^{34}$. Studies on murine models have also shown a synergistic effect in relation to virulence between both the bacteria ${ }^{36}$. Previous studies have shown that $P$. gingivalis co-aggregated with $F$. nucleatum in both in vivo and invitro ${ }^{36}$. These studies also examined the ability of $P$. gingivalis and $F$. nucleatum in inducing experimental periodontitis in mice ${ }^{36}$. They infected mice orally with $P$. gingivalis and $F$. nucleatum alone and as a mixed infection ${ }^{36}$. No significant bone loss has been observed in mice infected only with either $P$. gingivalis or $F$. nucleatum alone which was similar to non- infected group of mice ${ }^{36}$. But the group of mice which were infected with a mixed infection of both $P$. gingivalis and $F$. nucleatum exhibited a significant alveolar bone loss compared to the sham-infected control group of mice and the group of mice which were infected with either only $P$. gingivalis or F. nucleatum alone ${ }^{36}$. Though the same concentration of bacteria are used in mixed infection and mono-infection experiments the reason for significant alveolar bone loss in mixed infection group of mice might be because of the synergism in virulence between $P$. gingivalis and $F$. nucleatum ${ }^{36}$. 
Significance of Porphyromonas gingivalis and Streptococcus gordonii interaction in Dental plaque biofilm formation - Important facts and observations from previous research studies:

Previous studies showed that $P$. gingivalis adheres to $S$. gordonii through the interaction of the minor fimbrial antigen Mfa1 with a specific region of SspB polypeptide (residues 1167-1193) designated BAR ${ }^{37}$.

SspB polypeptide is a "multi-functional polypeptide" which is 1500 residues in length and is the chief cell surface protein belonging to the antigen I/II family ${ }^{38}$. These studies also showed that an interaction between SspB polypeptide and a mucin like salivary glyco protein in a calcium-dependent reaction is crucial for the adherence of Streptococcus gordonii cells with the oral mucosal surface ${ }^{38}$.

$P$. gingivalis interaction with $F$. nucleatum is facilitated by a galactose specific lectin ${ }^{39}$ whereas its interaction with $S$. gordonii is "multimodal". The binding mechanism between $P$. gingivalis and S. gordonii involves the major fimbrial Fim A protein which extends $3 \mu \mathrm{m}$ from the cell surface and the species specific interaction between minor fimbrial Mfa1 protein and the streptococcal SspB polypeptide ${ }^{13}$." The minor fimbrial antigen Mfa1 protein extends only $0.1-0.5 \mu \mathrm{m}$ from the cell surface ${ }^{40,41}$. Though both the P. gingivalis major fimbrial Fim A protein and minor fimbrial Mfa1 protein interact with S. gordonii, the interaction of minor fimbrial Mfa1 protein with a specific region of the streptococcal SspB polypeptide is much more significant when compared to major fimbrial Fim A protein which binds with isogenic Ssp null mutant of S. gordonii DL1 ${ }^{42}$. This is because the Mfa1- SspB interaction is crucial for the induction of $P$. gingivalis biofilms on 
streptococcal substrate whereas the interaction between $P$. gingivalis major fimbrial Fim A and isogenic Ssp null mutant of S. gordonii was unable to support biofilm growth ${ }^{42}$.

A synthetic peptide was designed based on the BAR sequence which is a specific region of the streptococcal SspB polypeptide (residues 1167 to 1193$)^{37}$. This specific region of streptococcal SspB polypeptide is known to interact with the minor fimbrial antigen Mfal of $P$. gingivalis thus facilitating the adherence of gram negative anaerobic organism- $P$. gingivalis with the gram positive aerobic cocci- $S$. gordonii ${ }^{37,38}$. Our previous invitro research studies showed that the synthetic BAR peptide potently inhibited the $P$. gingivalis Mfa1- S. gordonii SspB polypeptide interaction and also effectively reduced the depth of $P$. gingivalis micro-colonies formed in its presence ${ }^{37}$.

The specific inhibitory activity of BAR is influenced by several factors which when regulated might result in comparatively higher inhibitory activity of BAR. $P$. gingivalis expresses Lys-gingipains which might degrade the lysine residues present in the $\mathrm{BAR}^{37}$. In order to produce BAR peptides with more potent inhibitory activity, the L-amino acids in the BAR were replaced by D-amino acids and the direction of the BAR peptide backbone was reversed thus resulting in a BAR peptide which was designated as RI BAR ${ }^{37}$. But RI BAR proved to be ineffective not only at concentrations $1-10 \mu \mathrm{g} / \mathrm{ml}$ but even at higher concentrations of $50 \mu \mathrm{g} / \mathrm{ml}^{37}$. This indicates that only the native BAR but not its retroinverso analog can assume the functional conformation of $\mathrm{SspB}$ polypeptide that is recognized by the $P$. gingivalis minor fimbrial Mfa1 protein ${ }^{37}$. These studies also involved development of conformationally constrained analog of BAR - CR BAR which had the same chirality of BAR but leucine residues at positions 1177 and 1191 were replaced with cysteine residues $^{37}$. This resulted in cyclic disulfide bonds which limited the bond rotations 
within the peptide back bone of the NITVK sequence ${ }^{37}$. CR-BAR did not exhibit any significant inhibition at $10 \mu \mathrm{g} / \mathrm{ml}$ concentration whereas significant reduction in $P$. gingivalis micro colony formation on streptococcal substrate was observed at $50 \mu \mathrm{g} / \mathrm{ml}$ of concentration $^{37}$. Furthermore experiments were conducted involving the functional screening of combinatorial libraries of BAR. This included the replacement of active site residues (Asn1182, Thr1184, and Val1185) with each of the 19 common aminoacids ${ }^{37}$. The structural information obtained from these experiments that might be useful for further studies was

i. Replacement of Asparginine at position 1182 with positively charged amino acids and substitution of Valine at position 1185 with hydrophobic residues promotes the adherence of $P$. gingivalis to the BAR peptide ${ }^{37}$.

ii. Substitution of the same amino acids with Proline or glycine was detrimental to the adherence of $P$. gingivalis to the BAR peptide ${ }^{37}$.

iii. The effect of substitutions at Threonine was less prominent either positively or negatively compared to the other positions. This indicated that electrostatic forces and hydrophobic interactions contributed to Mfa1-SspB interaction ${ }^{37}$.

Using structural information obtained from the previous studies a BAR peptide was developed by substituting Asparginine at position 1182 with Arginine and Valine at position 1185 with Isoleucine which was designated BAR II. This BAR peptide analog when tested exhibited higher inhibitory activity of $P$. gingivalis Mfa1- streptococcal SspB interaction when compared to BAR peptide ${ }^{43}$. Further studies were conducted to determine the importance of secondary structure of BAR as a part of which the predicted secondary 
structures of the BAR peptide and BAR II were compared ${ }^{43}$. The presence of Arginine and Isoleucine facilitated stabilization of the secondary structure of BAR in BAR II which resulted in a significantly greater $\alpha$ - helical content and less $\beta$ sheet and random coil in solution $^{43}$. In order to determine if the BAR- mediated inhibition of $P$. gingivalis interaction with $\mathrm{SspB}$ polypeptide is connected to $\alpha$ - helical content, the conformationally constrained analog CR BAR which was developed in the previous studies is examined ${ }^{43}$. This study showed that CR BAR also contained 28\% $\alpha$ helical content which suggested that the inhibitory activity is either independent of the secondary structure or substitution of leucine residues with cysteine residues to produce CR BAR disrupted the secondary structural motif important for the $P$. gingivalis- BAR interaction ${ }^{43}$. To determine this further studies were conducted aiming on the region that were changed to generate CR $\mathrm{BAR}^{36}$. These studies showed that substitution of leucine residues with cysteine residues to produce $\mathrm{CR}$ BAR disrupted the secondary structural motif important for the $P$. gingivalis- BAR interaction ${ }^{43}$. This is because one of the leucine residues that was substituted with cysteine residue at position 1177 was part of a predicted amphipathic $\alpha$ helix that was similar to a known protein- protein interaction domain, the NR Box ${ }^{43}$. Previous studies have already shown that the NITVK motif is responsible for the $P$. gingivalis selective adherence to oral streptococci ${ }^{37}$. Further studies conducted to determine if the VXXLL region contributes to the interaction of BAR with $P$. gingivalis showed that both the motifs NITVK and VQDLL are required for the interaction of $P$. gingivalis with $\mathrm{BAR}^{43}$. In addition the structural characteristics and the sequence of the VXXLL motif in BAR was consistent with the consensus NR BOX ${ }^{43}$. Incorporation of amino acids possessing the properties to disrupt the secondary structure of VXXLL 
resulted in a reduction in the specific inhibitory activity of BAR which indicates that the putative $\alpha$-helical character of VXXLL is essential for the Mfa1- BAR interaction ${ }^{43}$.

The VXXLL motif is also flanked by Lys residues at the $-1,-2,+6$ and +7 positions, and the substitution of acidic amino acids at these positions led to reduced inhibitory activity $^{43}$. This suggested that the BAR-Mfa1 interaction may also be stabilized by a charge clamp comprising the flanking Lys residues ${ }^{43}$. Furthermore the specificity of the coactivator-NR interaction is led by amino acids that are present either upstream or downstream from the core LXXLL motif ${ }^{44}$. The VXXLL motif in BAR is present immediately upstream from NITVK, which is responsible for the specificity of $P$. gingivalis adherence to the oralis group of streptococci ${ }^{44}$.

In total these results suggest that $P$. gingivalis- streptococci interaction is facilitated by a protein-protein interacting domain of $\mathrm{SspB}$ (antigen I/II) that resembles the eukaryotic NR box domain ${ }^{43}$. These studies suggest that the modification of the VXXLL and NITVK motifs, either to restrict the flexibility of the peptide or to maintain its $\alpha$-helical character, might result in BAR peptide analogs with higher specific inhibitory activity ${ }^{43}$. Together these studies suggested that the specific region of the SspB cell surface protein of streptococcal antigen I/II comprises of two motifs - KKVQDLLKK and NITVK motifs and that both the motifs have to be considered in developing potent structurally modified BAR peptide analogs that target the $P$. gingivalis adherence onto streptococcal substrate and subsequent biofilm formation ${ }^{43}$. 


\section{CHAPTER - 2 \\ HYPOTHESIS AND AIMS}

The colonization of Porphyromonas gingivalis is the key phase in the transformation of the bacterial biofilm from a commensal plaque to the pathogenic form observed in periodontitis. As mentioned in the previous chapter, previous studies have shown that $P$. gingivalis adheres to S. gordonii through the interaction of the minor fimbrial antigen Mfa1 with a discrete region of the $\mathrm{SspB}$ polypeptide (residues 1167 to 1193) which is designated BAR ${ }^{37}$. Our previous studies have also shown that a synthetic peptide comprising the BAR sequence potently inhibits the interaction between P. gingivalis and S. gordonii and thus inhibiting the $P$. gingivalis biofilm formation ${ }^{37}$.

Assessment of the efficiency of the BAR peptide and it's analogs in inhibiting the $P$. gingivalis and S. gordonii interaction in a dual species biofilm and also in a more complex three species biofilm having $F$. nucleatum as the third species gives us valuable information to progress in the path to produce potent therapeutic compounds that might prevent or limit periodontal disease. F. nucleatum was chosen as the third species for a more complex three species biofilm culture system as it is considered to be a microbial bridge that coaggregates with not just "oxygen-tolerant and other obligatory anaerobic species but also with otherwise- non co- aggregating obligate anaerobe-oxygen-tolerant species pairs" ${ }^{24}$. 


\section{Statement of Objectives and Hypothesis:}

The goals of this study are to establish optimum levels of P. gingivalis, S. gordonii and $F$. nucleatum to reproducibly generate dual and three species complex biofilms and to examine inhibition of their formation by BAR peptide and its analogs (1) $\mathrm{C}_{1-24} \mathrm{R}_{1182} \mathrm{I}_{1185}$ BAR, (2) $\mathrm{R}_{1182} \mathrm{I}_{1185} \mathrm{BAR}$ and (3) $\mathrm{C}_{1-24}$

\section{Research Hypothesis:}

Our hypothesis is that the structural information obtained from BAR peptide can be used to develop more potent inhibitors that target both simple and complex $P$. gingivalis biofilms and that preventing the $S$. gordonii- $P$. gingivalis interaction may influence the formation of more complex biofilms

\section{Specific Aims:}

The Specific aims of the study were as follows:

1. For simple dual species bio-film the aim is to establish optimum levels of $S$. gordonii and $P$. gingivalis in order to readily produce dual species biofilm and to test the efficiency of the structurally modified BAR peptides (1) $\mathrm{C}_{1-24} \mathrm{R}_{1182} \mathrm{I}_{1185}$ BAR, (2) $\mathrm{R}_{1182} \mathrm{I}_{1185} \mathrm{BAR}$ and (3) $\mathrm{C}_{1-24}$ in more potently inhibiting $P$. gingivalis $-S$. gordonii dual species biofilm formation relative to parent BAR peptide.

2. For three species complex biofilm the aim is to establish experimental conditions and optimum levels of $S$. gordonii, $P$. gingivalis and $F$. nucleatum to reproducibly generate three species complex biofilm and to test the efficiency of parent BAR and 
it's analogs (1) $\mathrm{C}_{1-24} \mathrm{R}_{1182} \mathrm{I}_{1185} \mathrm{BAR}$, (2) $\mathrm{R}_{1182} \mathrm{I}_{1185}$ BAR and (3) $\mathrm{C}_{1-24}$ in inhibition of $P$. gingivalis and $S$. gordonii interaction in a three species complex biofilm and to determine if blocking $S$. gordonii- $P$. gingivalis interaction alters the formation of three species biofilms. 


\section{CHAPTER 3}

\section{MATERIALS AND METHODS}

\section{Dual species biofilm:}

Porphyromonas gingivalis ATCC 33277 is a strain which is extensively used throughout many periodontal research studies. Therefore it was grown anaerobically in pre- reduced Trypticase Soy broth media (TSBY media) (Difco) supplemented with $0.5 \%$ yeast extract, hemin and menadione without shaking for 48 hours at $37^{\circ} \mathrm{C}$. For this purpose, a ten milliliter sample of the TSBY media was pre- reduced under anaerobic conditions for 24 hours by equilibration in an atmosphere consisting of $10 \% \mathrm{CO}_{2}, 10 \% \mathrm{H}_{2}$, and $80 \% \mathrm{~N}_{2}$.

Alternatively $P$. gingivalis was cultured using fresh Trypticase soy broth media blood agar plates which were pre- reduced and streaked using frozen stocks of $P$. gingivalis ATCC 33277. P. gingivalis grown by either of the above mentioned methods was subcultured into twenty milliliters of fresh pre-reduced TSBY media supplemented with yeast, hemin and menadione. It was grown anaerobically for 48 hours without shaking at $37^{\circ} \mathrm{C}$.

Streptococcus gordonii DL-1 was cultured aerobically in ten milliliter samples of Brain heart infusion broth supplemented with $1 \%$ yeast extract (BHIY) without shaking O/N. For inoculation of S. gordonii, frozen stocks of Streptococcus gordonii DL- 1 strain were used. Alternatively Streptococcus gordonii DL- 1 was cultured using fresh Brain heart infusion media blood agar plates which were streaked using the frozen stocks of S. gordonii 
DL- 1. S. gordonii grown by either of the above mentioned methods was sub-cultured into twenty five milliliter of BHIY and grown aerobically- O/N, without shaking.

After sub-culturing Streptococcus gordonii, a $1.5 \mathrm{ml}$ aliquot was dispersed into a $2 \mathrm{ml}$ eppendorf tubes a centrifuged at 5600 RPM for 5minutes. The supernatant was discarded and the cell pellet was re- suspended in $1 \mathrm{ml}$ of $1 \mathrm{X}$ Phosphate buffer saline (1X PBS). $S$. gordonii was labeled with $3 \mu 1-5 \mu 1$ of $10 \mathrm{mM}$ Hexidium iodide $(5 \mathrm{mg} / \mathrm{ml}$, Molecular probes) for every $3 \mathrm{ml}$ of $S$. gordonii culture used. After the $S$. gordonii cells were labeled - cells were incubated for 15 minutes at room temperature on a rocker platform protected from light. Throughout the procedure the cells were protected from light by working in dim light and covering the samples with aluminum foil. Following this incubation, the labeled cells were centrifuged at 5600 RPM for 5minutes, and the supernatant was discarded and the cells were re-suspended in $1 \mathrm{ml}$ of $1 \mathrm{X}$ PBS. The optical density (O.D) at $600 \mathrm{~nm}$ of the cells was checked at 1:10 dilution of S. gordonii cells.

For establishing the optimum inocula for $S$. gordonii cells, biofilms were formed using $S$. gordonii at different optical densities including $0.1,0.2,0.5$ and 0.8 and the optimal conditions were found to use an optical density of 0.8 for $S$. gordonii. Formation of a uniform confluent layer of $S$. gordonii was taken as criteria for the selection of optimum optical density.

All the subsequent experiments were carried out using the optimal conditions identified above. The optical density of $S$. gordonii was adjusted to 0.8 using 1 X PBS.A 12 well culture plate (cell treat cell culture plate) - was taken with 1 each of a sterilized micro cover slip added to each well. $1 \mathrm{ml}$ each of the labeled Streptococcus gordonii cells with optical density 0.8 was added into each appropriate well in the 12 well culture plate. 
The 12 well cell culture plate was covered with aluminum foil in order to protect the labeled cells from light and then placed on a rocker platform on the lowest possible rocker setting in the anaerobic chamber at $37^{\circ} \mathrm{C}$ and incubated for $18-24$ hours. On the same day autoclaved 1X PBS was pre-reduced in the anaerobic chamber to be used for the following procedure.

The amount of $P$. gingivalis used for biofilm culture was optimized using a similar approach. P. gingivalis cells sub- cultured and grown under anaerobic conditions were taken and $1.5 \mathrm{ml}$ aliquots was dispersed into a $2 \mathrm{ml}$ eppendorf tubes and centrifuged for 5min at 5600 RPM. Pre-reduced 1XPBS was used throughout the procedure. The supernatant was discarded and cell pellet was re-suspended into $1 \mathrm{ml}$ of pre-reduced $1 \mathrm{X}$ PBS. P. gingivalis cells were labeled with $1 \mu 1-3 \mu 1$ of 5-(6) carboxyfluorescein succinylester (4mg/ml, Molecular probes) for every $3 \mathrm{ml}$ of $P$. gingivalis culture used. After the $P$. gingivalis cells were labeled - cells were incubated for 30 minutes at room temperature on a rocker platform protected from light. Throughout the procedure the cells were protected from light by working in a dim light and covering the samples with aluminum foil. Following the incubation the labelled cells were centrifuged at 10000 RPM for 1 minute and the supernatant was discarded and the cells were re-suspended in $1 \mathrm{ml}$ of pre- reduced $1 \mathrm{X}$ PBS. The optical density (O.D) at $600 \mathrm{~nm}$ of the cells was checked at a 1:10 dilution of $P$. gingivalis cells.

For establishing the optimum inocula for $P$. gingivalis cells, various experiments were done using dual species biofilms which were formed using $P$. gingivalis cells at various optical densities that include $0.05,0.1,0.2,0.5$ and0.8. The optimal conditions were found to use an optical density of 0.1 for $P$. gingivalis cells. A uniform distribution of 
distinct micro colonies of $P$. gingivalis adhering to the streptococcal substratum was taken as the criteria for choosing the ideal conditions.

All the subsequent experiments were carried out using the optimal conditions identified above. The optical density was adjusted to 0.1 using 1 XPBS.

For the control biofilm the sample at this stage was added $1 \mathrm{ml}$ each into each well of the 12 well cell culture plate after the removal of the supernatant from the previous day.

For biofilm inhibition experiments, BAR peptide and BAR peptide analogs were pre-incubated with labeled $P$. gingivalis cells at concentrations of 0 to $10 \mu \mathrm{g}$ per $\mathrm{ml}$ at $25^{\circ} \mathrm{C}$ for 30 min before adding to the appropriate wells. The 12 well cell culture plate was covered with aluminum foil and incubated for 18-24 hours in the anaerobic chamber similar to previous day. 1X PBS was pre-reduced for the next step in the procedure.

Following 18- 24 hours of incubation the supernatant was removed from the wells of the 12 well cell culture plate and the cells were washed with $1 \mathrm{ml}$ of pre-reduced 1XPBS to remove any non- adherent bacterial cells. Following the wash $4 \%$ paraformaldehyde solution was added $1 \mathrm{ml}$ each to each well. This solution serves to fix the cells. After 5minutes the paraformaldehyde solution was removed and the cells were washed with prereduced $1 \mathrm{X}$ phosphate buffer saline. Following this procedure, the cover slip was mounted on to a slide glass using Prolong gold anti-fade reagent.

Under these conditions, the streptococci formed a confluent layer on the micro coverslip. $P$. gingivalis subsequently formed distinct micro colonies on the streptococci which were quantified by confocal microscopy as described below. 


\section{Confocal Laser scanning Microscopy:}

P. gingivalis-S. gordonii biofilms were visualized and imaged using an Olympus Fluoview 500 confocal laser scanning microscope (Olympus, Pittsburgh, PA). Confocal laser scanning microscopy was chosen for imaging because of its high-resolution optical images with depth selectivity. It produces blur-free images of thick specimens at various depths ${ }^{45}$. It acquires in-focus images at selected depths and this process is known as optical sectioning. Images are taken point-by-point and reassembled with a computer, rather than projected through an eyepiece which facilitates the three dimensional imaging and reconstruction of topologically complex objects $^{45}$. CLSM is widely used in numerous biological science disciplines.

The slides were viewed under the confocal laser scanning microscopy and $\mathrm{z}$ stack images were formed. All the slides were viewed using a $60 \times$ objective lens using an argon laser for visualization of FITC labeling and the HeNe-G laser to visualize hexidium iodidelabeled streptococci. The number and height of FITC-labeled P. gingivalis microcolonies were determined from 30 to 60 randomly chosen frames using the FluoView software package provided by Olympus. Microcolony depth was determined by performing z-plane scans from $0 \mu \mathrm{m}$ to $30 \mu \mathrm{m}$ above the cover glass surface. P. gingivalis micro colonies that formed on $S$. gordonii in the absence of inhibitor ranged from 4 to $19 \mu \mathrm{m}$ in depth under the experimental conditions used. We used an image resolution of $1024 \times 1024$. We used a Fast scan speed as slow scan speeds also increase the amount of time required to capture an image and may increase the risk of photo toxicity. Background noise- if any present was removed using the volocity software during image processing. The Z-step size used 
was $0.7 \mu \mathrm{m}$. Image acquisition of z-stacks of optical slices of the biofilms was done and images were analyzed using volocity software.

\section{Image Analysis:}

After the images were captured by confocal laser scanning microscopy the resulting optical slices were digitally processed and reconstructed in 3D using Volocity software. 3D data analysis in z-stacks of optical slices could overcome the majority of classification errors associated with $\mathrm{x}$ and $\mathrm{y}$, but requires advanced software and high volume data management. Volocity is one of several commercially available advanced high performance 3D-4D image analysis software packages that can measure all volumetric pixels (i.e. voxels in total volume of z-stacks of optical sections) and therefore gain better signal overlap detection in all $\mathrm{x}, \mathrm{y}$ and $\mathrm{z}$ axes improving compiling of cell structures as well as fate classification.

Images were imported into Volocity as multiple tiff- file format. The software supports several other image acquisition platform file formats. A uniform filter was used to remove noise from the system and measurements were performed to identify cells. The image brightness and contrast enhancement options were used for high quality images and a snapshot of image was captured which was used to measure the volume of the bacteria. In the process of analyzing as this was dual species biofilm we selected two channel and assigned respective fluorescent dyes with which the bacteria were labeled and then the images were analyzed with the following basic settings: i. Restrict Analysis to - All populations, ii. Summarized by - Sum, iii. Row- Population. The obtained data was exported and saved and the images were exported as snapshot and saved in Jpeg format. 
This is a highly helpful tool using which we analyzed data for measuring the effectiveness of BAR peptides and its analogs in inhibiting the $S$. gordonii and $P$. gingivalis experiments.

\section{Data Analysis:}

Once the values in relation to population or volume of each bacteria were obtained, the mean and Standard deviation of $S$. gordonii values and $P$. gingivalis values were measured and the average volume of $P$. gingivalis per average volume of $S$. gordonii was determined. This indicates the volume of $P$. gingivalis present per a given amount $S$. gordonii.

Based on these values, the percentage of inhibitory activity of the BAR peptide and the peptide analogs $1 . \mathrm{C}_{1-24} \mathrm{R}_{1182} \mathrm{I}_{1185} \mathrm{BAR}, 2 . \mathrm{R}_{1182} \mathrm{I}_{1185} \mathrm{BAR}$ and $3 . \mathrm{C}_{1-24} \mathrm{BAR}$ at concentrations $1 \mu \mathrm{g} / \mathrm{ml}, 5 \mu \mathrm{g} / \mathrm{ml}$ and $10 \mu \mathrm{g} / \mathrm{ml}$ was determined. To determine if the rate of inhibition of BAR peptide analogs was statistically significant compared to BAR peptide two tailed t-tests with significance level $5 \%(\alpha=0.05)$ were performed with significance level on the data sets using Microsoft Excel Analysis Toolpak.

\section{Synthesis of peptides and combinatorial peptide libraries.}

The peptides that were used in this study are shown in Fig. 1 as shown in pg. 25. The BAR peptide (Fig. 1A.) and its analogs (Fig. 1B, 1C, 1D.) were synthesized by Biosynthesis, Inc. (Lewisville, TX). All peptides were obtained at greater than $90 \%$ purity. The BAR peptide comprises amino acids 1167 to 1193 of the $S$. gordonii SspB polypeptide (Fig 1A.).

Three structurally modified BAR peptide analogs which were synthesized using the structural information from the BAR peptide were chosen for our research studies. 
They are as follows:

1. $\mathrm{C}_{1-24} \mathrm{R}_{1182} \mathrm{I}_{1185} \mathrm{BAR}$

2. $\mathrm{R}_{1182} \mathrm{I}_{1185} \mathrm{BAR}$ and

3. $\mathrm{C}_{1-24} \mathrm{BAR}$

$\mathrm{C}_{1-24} \mathrm{R}_{1182} \mathrm{I}_{1185} \mathrm{BAR}$ peptide was synthesized by replacing the leucine residues at positions 1167 and 1191 with cysteine. This resulted in a cyclic disulfide bond that limited bond rotations within the peptide backbone of the intervening active site NITVK sequence $^{30}$. In addition, asparginine is replaced by arginine at position 1182 and valine at position 1185 is replaced by isoleucine. Arginine $(\mathrm{R})$ is a positively charged amino acid and isoleucine is a hydrophobic residue. Previous studies showed a BAR peptide analog CR BAR whose leucine residues at positions 1177 and 1191 when substituted by cysteine residues exhibited poor inhibitory activity ${ }^{37}$. This was due to the fact that leucine residue at position 1177 is a part of a motif, VXXLL that resembles a known protein -protein interacting domain, the NR box found in coactivators of NRs of eukaryotes ${ }^{43}$. Substitution of this leucine residue at position 1177 with cysteine caused disruption of the second important region of the BAR that is required for $P$. gingivalis adhesion ${ }^{43}$.

Therefore in developing the current BAR peptide analog only the leucine residues at position 1167 and 1191 are substituted with cysteine molecules preventing the disruption of $\alpha$-helicity of BAR. The peptide sequence of this BAR peptide analog is as shown in Fig. 1B. 


\title{
Figure 1
}

\section{(A). LEAAPKKVQDLLKKANITVKGAFQLFS}

\author{
(B). CEAAPKKVQDLLKKARITIKGAFQCFS
}

\section{(C). LEAAPKKVQDLLKKARITIKGAFQLFS}

\section{(D). CEAAPKKVQDLLKKANITVKGAFQCFS}

FIG. 1. (A) Sequence of BAR peptide used in this study. BAR peptide is comprised of amino acid residues 1167 to 1193 of the $S$. gordonii SspB protein. The underlined sequence, NITVK, represents active site residues involved in the adherence of $P$. gingivalis to SspB and BAR with Asn at position 1182 and Val at position 1185. (B). Sequence of BAR peptide analog $\mathrm{C}_{1-24} \mathrm{R}_{1182} \mathrm{I}_{1185} \mathrm{BAR}$. The leucine residues at positions 1167 and 1191 were replaced with cysteine and Asn at position 1182 is replaced by Arginine and Valine at position 1185 replaced with Isoleucine.

(C). Sequence of BAR peptide analog $\mathrm{R}_{1182} \mathrm{I}_{1185}$ BAR. Asn at position 1182 is replaced by Arginine, Valine at position 1185 replaced with Isoleucine. Leucine residues remain unchanged

(D). Sequence of BAR peptide analog $\mathrm{C}_{1-24} \mathrm{BAR}$. The leucine residues at positions 1167 and 1191 of the BAR peptide were replaced with cysteine. Asn and Val at positions 1182 and 1185 remain unchanged. 
$\mathrm{R}_{1182} \mathrm{I}_{1185}$ BAR was synthesized by substituting Asn at position 1182 with positively charged amino acid Arg and substituting Val at position 1185 with hydrophobic amino acid Ile which were shown to promote $P$. gingivalis adherence to BAR. In this BAR peptide analog the leucine residues were not substituted with cysteine. The peptide sequence of this BAR peptide analog is as shown in Fig. 1C.

$\mathrm{C}_{1-24} \mathrm{BAR}$ was synthesized by substituting the leucine residues at positions 1167 and 1191 with cysteine thus resulting in a cyclic disulfide bond that limits the bond rotation within the peptide backbone of the intervening active site NITVK sequence. Asn at 1182 position and Val at position 1185 were not replaced. The peptide sequence of this BAR peptide analog is as shown in Fig. 1D.

\section{Three species biofilm:}

Fusobacterium nucleatum was chosen for three species biofilm experiments because of its ability to adhere to both gram positive and gram negative plaque forming microorganisms and previous studies demonstrated its ability to co-aggregate with suspected periodontal pathogens.

P. gingivalis and S. gordonii were grown as previously described for the dual species biofilm cultures. F. nucleatum was grown anaerobically in pre- reduced Brain heart infusion media (BHI media) (Difco) supplemented with hemin and menadione without shaking for 96 hours at $37^{\circ} \mathrm{C}$. For this purpose, a twenty five milliliter sample of the TSBY media was pre- reduced under anaerobic conditions for 24 hours by equilibration in an atmosphere consisting of $10 \% \mathrm{CO} 2,10 \% \mathrm{H} 2$, and $80 \% \mathrm{~N} 2$. Pre-reduced medium was inoculated using frozen stocks of $F$. nucleatum. Alternatively $F$. nucleatum grown using 
fresh Brain heart infusion media (BHI) blood agar plates which were pre- reduced and streaked using frozen stocks of $F$. nucleatum may be used instead of the frozen stocks for inoculation.

The first step in three species biofilm was addition and incubation of S. gordonii cultures in the 12 well cell culture plate as described in the dual species biofilm. The same day $F$. nucleatum cultures grown anaerobically for 72- 96 hours without shaking were removed from the anaerobic chamber and centrifuged for 20minutes at 3000RPM. The supernatant was discarded and the cell pellet formed was re-suspended in 1ml of 1X PBS. DDAO-SE (Molecular probes) which is a fixable far red fluorescent tracer was chosen to label $F$. nucleatum cells. The optical density (O.D) at $600 \mathrm{~nm}$ of the cells was checked at a 1:10 dilution of $F$. nucleatum cells.

For establishing the optimum inocula for $F$. nucleatum cells, three species biofilms were formed using $F$. nucleatum cells at various optical densities that include $0.1,0.2,0.5$ and1.0 and 2.0. A uniformly distributed attachment of $F$. nucleatum cells to both $S$. gordonii and $P$. gingivalis forming thick complex biofilms was observed at an optical density of 2.0 which was chosen for our experiments. All subsequent experiments were carried out using the optimal conditions identified above.

F. nucleatum samples at O.D 2.0 were labeled with 2mM DDAO-SE. The amount of DDAO-SE was calculated based on two factors as follows:

1. 3- $4 \mu \mathrm{l}$ of DDAO-SE for every $3 \mathrm{ml}$ of $F$. nucleatum cultures used initially before the centrifugation. 
2. The volume of $F$. nucleatum cells taken from the $1 \mathrm{ml} F$. nucleatum solution formed by re-suspending the pellet in $1 \mathrm{ml} 1 \mathrm{X}$ PBS as described earlier.

The labeled $F$. nucleatum cells were protected from light with aluminum foil and placed on the rocker platform separately along with the 12 well cell culture plate with $S$. gordonii cells. The rocker platform is maintained at the lowest possible rocker setting. 1X PBS were pre- reduced for the next step.

For establishing the optimum inocula for Porphyromonas gingivalis for the three species complex biofilm, three species biofilms were formed with $P$. gingivalis cells at various optical densities that include $0.1,0.2,0.5$ and 1.0. The optimal conditions were found to use an optical density of 0.2 for $P$. gingivalis cells based on uniform distribution and distinct microcolony formation on streptococcal substrate.

Following an incubation period of 18- 24 hours of $S$. gordonii cells, the supernatant from the previous day was removed before the labeled $P$. gingivalis cells and labeled $F$. nucleatum cells were added simultaneously to each necessary well. This forms the three species biofilm on the micro coverslip which acts as a control in the experiments.

The $P$. gingivalis control sample and samples with BAR peptide or its analogs were prepared as described in dual species biofilms with an exception that the optical density for $P$. gingivalis used here is 0.2 for the formation of complex biofilm. The $F$. nucleatum sample of optical density 2.0 is prepared from the labeled cells and pre-reduced 1X PBS. Following this, the samples were added at $1 \mathrm{ml}$ each simultaneously into the respective wells of the 12 well cell culture plate after the supernatant from the previous day was removed. Throughout the procedure the labeled cells were protected from light. Pre- 
reduced $1 \mathrm{X}$ PBS was used throughout the procedure as necessary. After the samples were added, the 12 well cell culture plate is covered with an aluminum foil and was placed on a rocker platform with the lowest possible rocker setting. Incubation time is 18-24 hours.

After 18- 24 hours of incubation the 12 well cell culture plate is removed from the anaerobic chamber. The procedure for fixing and mounting of the micro coverslip onto the slide glass is as described in dual species biofilms.

The three species complex biofilms were viewed under confocal laser scanning microscopy. DDAO SE is excited by the far red 633nm laser. The dyes that were assigned to the three species while imaging are FITC to $P$. gingivalis, TEXAS RED to $S$. gordonii and CY5 to F. nucleatum. All the settings on confocal laser scanning microscope were as described in dual species biofilm. Images formed were saved and analyzed using volocity software. Analyzing a three species biofilm on volocity software is similar to dual species biofilm with an exception that in three species biofilm we select three channel setting and assign CY5 for the third bacterium along with FitC and Texas Red.

After the data was obtained, the average $S$. gordonii values, average $P$. gingivalis values, average $F$. nucleatum values were calculated after normalizing the average $S$. gordonii values. Based on these values, the percentage of inhibitory activity of the BAR peptide and peptide analogs 1. $\mathrm{C}_{1-24} \mathrm{R}_{1182} \mathrm{I}_{1185}$ BAR, 2. $\mathrm{R}_{1182} \mathrm{I}_{1185} \mathrm{BAR}, 3 . \mathrm{C}_{1-24} \mathrm{BAR}$ at concentrations $10 \mu \mathrm{g} / \mathrm{ml}, 25 \mu \mathrm{g} / \mathrm{ml}$ and $50 \mu \mathrm{g} / \mathrm{ml}$ were determined.

The various steps involved in three species biofilm are shown in Figure 2. 


\section{Figure 2.}

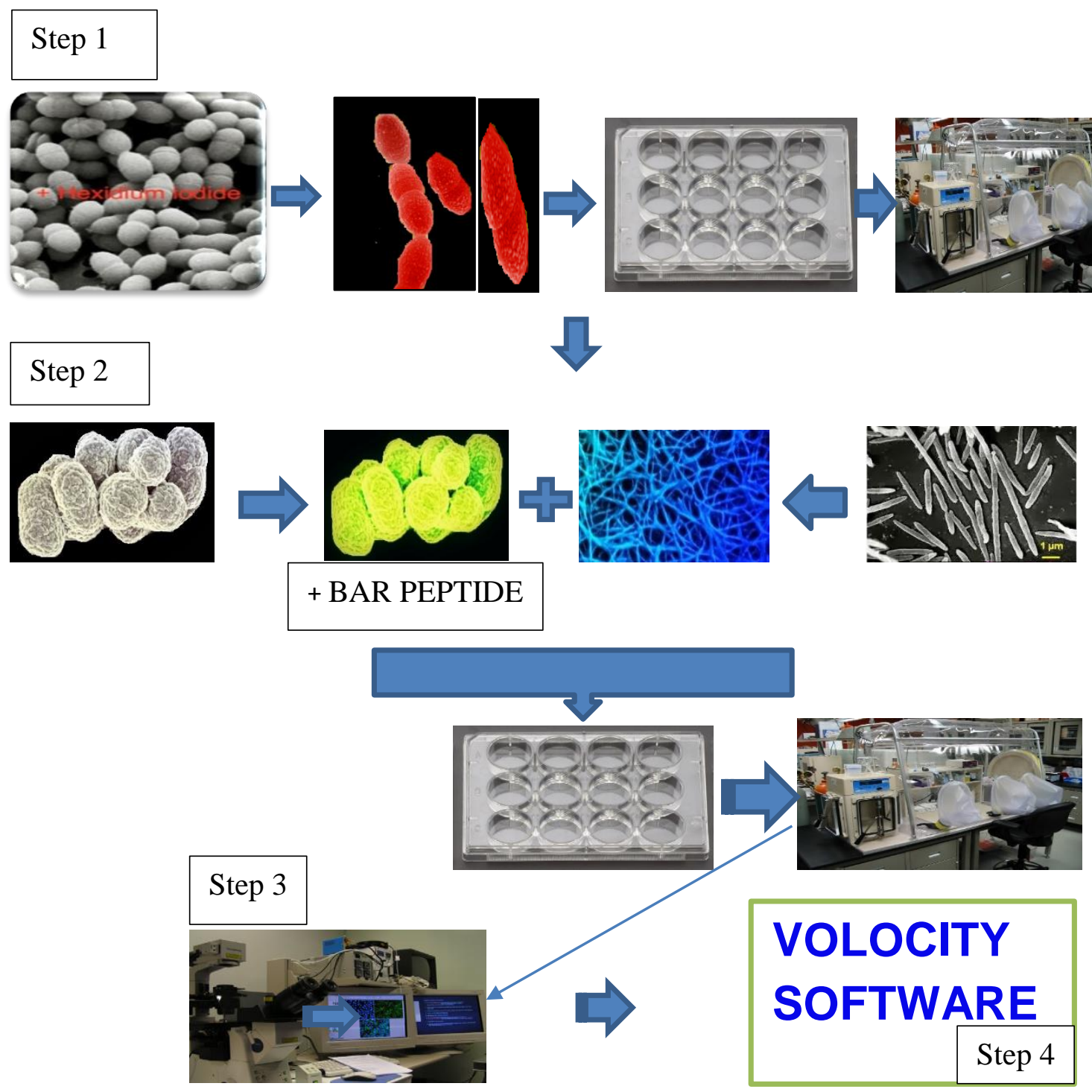

FIG. 2. Step 1-S. gordonii cells were labeled with Hexidium iodide and added to micro coverslips in 12 well cell culture plate followed by incubation under anaerobic conditions. Step 2- $P$. gingivalis cells labeled with carboxyfluorescein 5, 6- succinyl ester incubated with the respective BAR peptide and $F$. nucleatum cells labeled with DDAO- SE added to the micro coverslips after removal of supernatant followed by incubation under anaerobic conditions. Step 3- Micro coverslips are fixed and mounted onto slides and visualized under Olympus Fluoview FV500 Laser Scanning Microscopy. Step4- Optical slices formed under CLSM are reconstructed into 3D images using volocity software. 


\section{CHAPTER - 4}

\section{RESULTS}

\section{BAR peptide and its analogs inhibit formation of $\boldsymbol{P}$. gingivalis dual and three species complex biofilms.}

Our previous invitro studies have shown that a synthetic peptide comprising the BAR sequence potently inhibited the $P$. gingivalis Mfa1 $-S$. gordonii SspB interaction thus preventing $P$. gingivalis biofilm formation ${ }^{37}$. Subsequently functional screening of combinatorial libraries involving the replacement of three amino acids ( $\mathrm{Asn}^{1182}$, Thr1184, and $\mathrm{Val}^{1185}$ ) within active site NITVK region of BAR with each of the 19 common amino acids showed that positively charged amino acids at position 1182 and hydrophobic residues at position 1185 bound to $P$. gingivalis more efficiently when compared to the control peptide containing Asn and Val at these positions respectively ${ }^{37}$. Aspartate and proline were detrimental to $P$. gingivalis adherence at all three positions, and replacement of glycine at residues 1182 and 1184 reduced $P$. gingivalis adherence ${ }^{37}$.

The BAR peptide constitutes amino acid residues 1167 to 1193 of the $S$. gordonii SspB cell surface protein as shown in Fig. 1A. The amino acid residues which promoted $P$. gingivalis adherence to the BAR peptide and those which were detrimental to $P$. gingivalis adherence to the BAR peptide are shown in Fig. 3 
Further studies conducted to produce more potent inhibitors of $P$. gingivalis- $S$. gordonii Mfa1- SspB interaction have shown that along with NITVK motif a secondary structural motif VQDLL whose structural characteristics are consistent in consensus with the NR BOX was found to be essential for the Mfa1- BAR interaction ${ }^{43}$. The VQDLL is predicted to be a hydrophobic $\alpha$-helix ${ }^{43}$. Disrupting the secondary structure of VXXLL resulted in a decreased specific inhibitory activity of BAR suggesting that the putative $\alpha$ helical character is essential for the $P$. gingivalis Mfa1 interaction with the streptococcal SspB polypeptide ${ }^{43}$. Together these studies have shown that both the motifs KKVQDLLK and NITVK should be taken into account ${ }^{43}$ along with the other structural information obtained from the BAR peptide in the previous research studies, in developing structurally modified BAR peptide analogs that might act as potent inhibitors of $P$. gingivalis Mfa1- $S$. gordonii SspB interaction and biofilm formation.

To determine if the structural information obtained from the BAR peptide from previous studies could be exploited to produce more potent inhibitors of $P$. gingivalis biofilm formation, three structurally modified BAR peptide analogs were designed using the structural information from the BAR peptide as described in the previous chapter. They are- 1. $\mathrm{C}_{1-24} \mathrm{R}_{1182} \mathrm{I}_{1185} \mathrm{BAR}, 2$. $\mathrm{R}_{1182} \mathrm{I}_{1185} \mathrm{BAR}$ and 3. $\mathrm{C}_{1-24}$ BAR (Fig. 1.) 


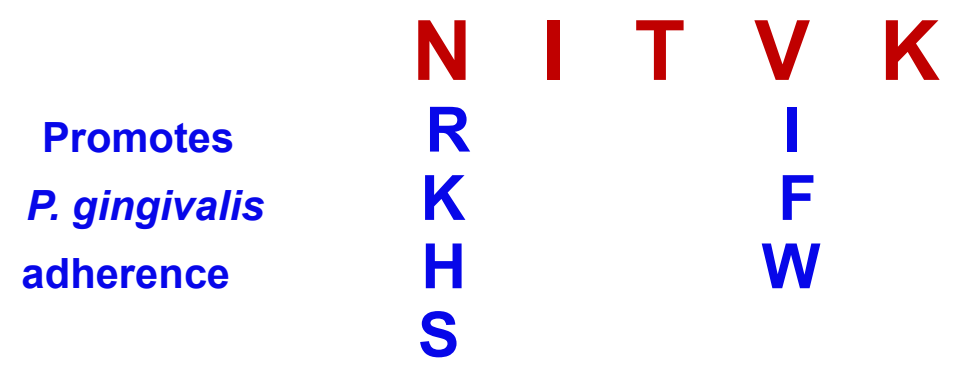

$\begin{array}{lccc}\text { Detrimental } & \text { D,E } & \text { D } & \text { D } \\ \text { to } P \text {. gingivalis } & \text { P } & \text { P } & \text { P } \\ \text { adherence } & \text { G } & \text { G } & \end{array}$

Figure 3. Screening of combinatorial libraries of BAR involved replacement of three active site residues $\mathrm{Asn}^{1182}, \mathrm{Thr}^{1184}$, and $\mathrm{Val}^{1185}$ with each of the 19 common amino acids ${ }^{37}$. This study conducted by Daep et. al resulted in peptide mixtures where position 1182 when substituted with positively charged aminoacids and when position 1185 was replaced by hydro-phobic amino acids as shown - it promoted $P$. gingivalis adherence to the BAR peptide ${ }^{37}$. In contrast Aspartic acid or proline at all the three positions were detrimental to $P$. gingivalis adherence ${ }^{37}$. Glycine at positions 1182 and 1184 was also detrimental to $P$. gingivalis adherence to BAR peptide ${ }^{37}$. 


\section{Dual Species Biofilm}

Our initial experiments were focused on establishing optimum inocula for $P$. gingivalis and $S$. gordonii to reproducibly generate dual species biofilms for testing the inhibitory activity of BAR peptide analogs when compared to the BAR peptide. To accomplish this we conducted various experiments using $S$. gordonii and $P$. gingivalis at various optical densities. S. gordonii was tested at optical densities that include $0.1,0.2$, 0.5, 0.8 and $P$. gingivalis was tested at optical densities that include $0.05,0.1,0.2$ and 0.5 as shown in Fig. 4. (A-J). The optimal conditions were found to use an optical density of 0.8 for $S$. gordonii and 0.1 for $P$. gingivalis to reproducibly generate dual species biofilms. At an optical density of $0.8, S$. gordonii formed a confluent uniform layer as shown in Fig. 4.B which was considered to be ideal for our experiments. At an optical density of $0.1, P$. gingivalis was found to have a uniform distribution with distinct micro colony formation adhering to the streptococcal substrate as shown in Fig. 4.H which was considered as ideal for our inhibition experiments. 

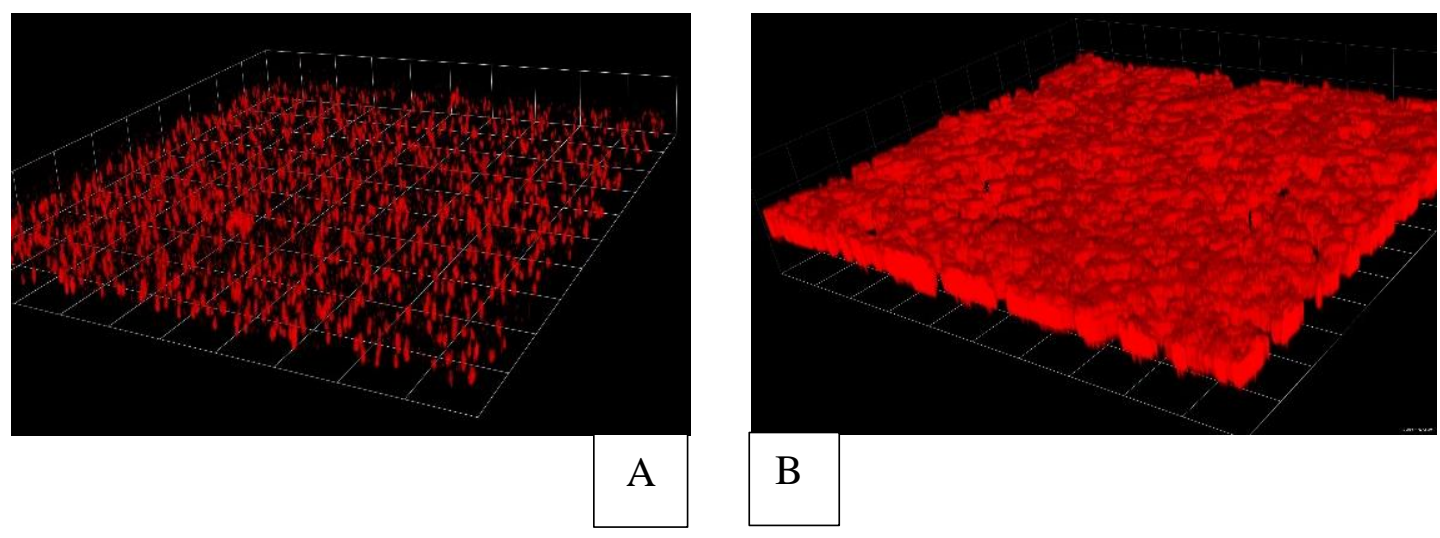

A $B$


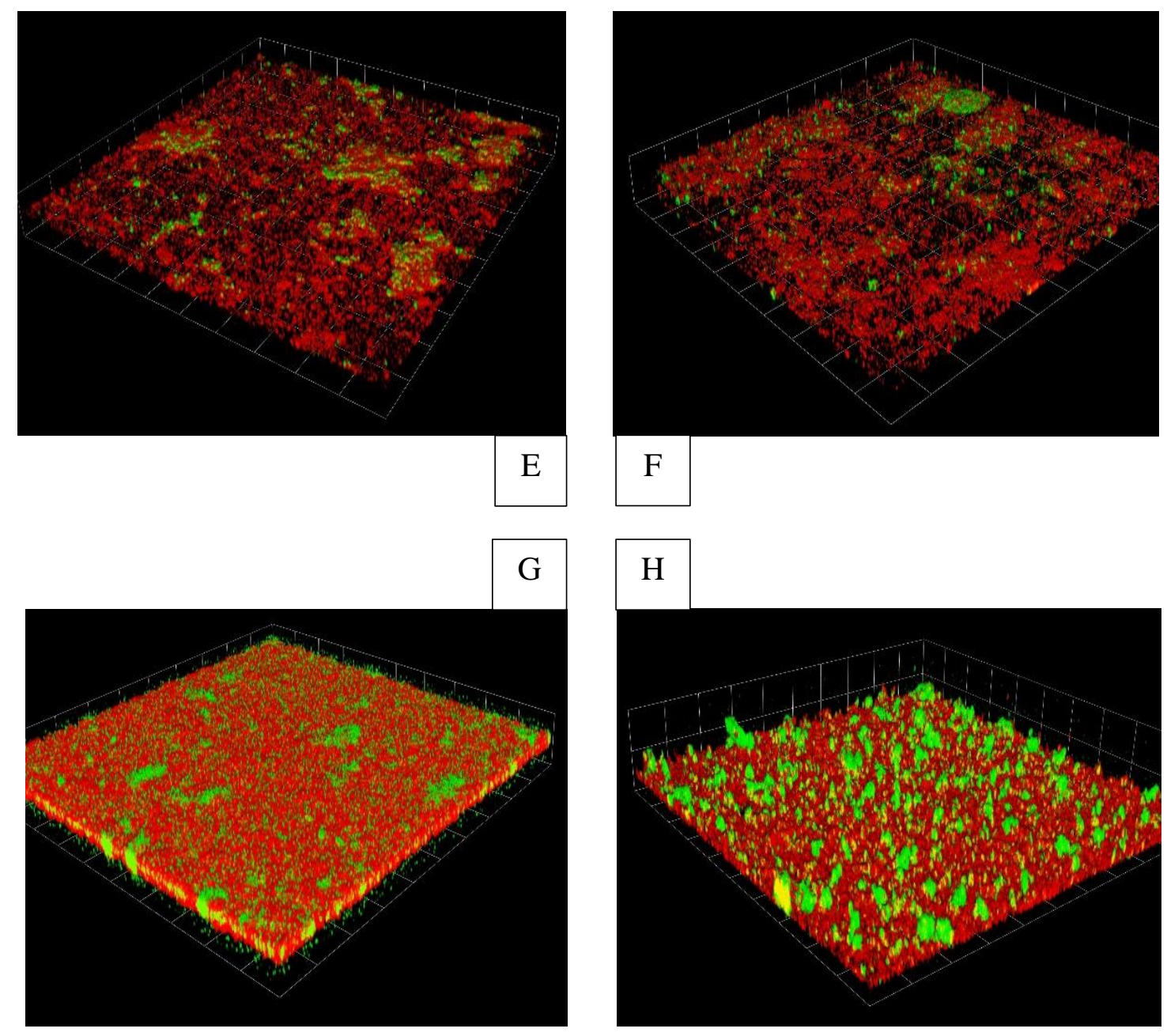

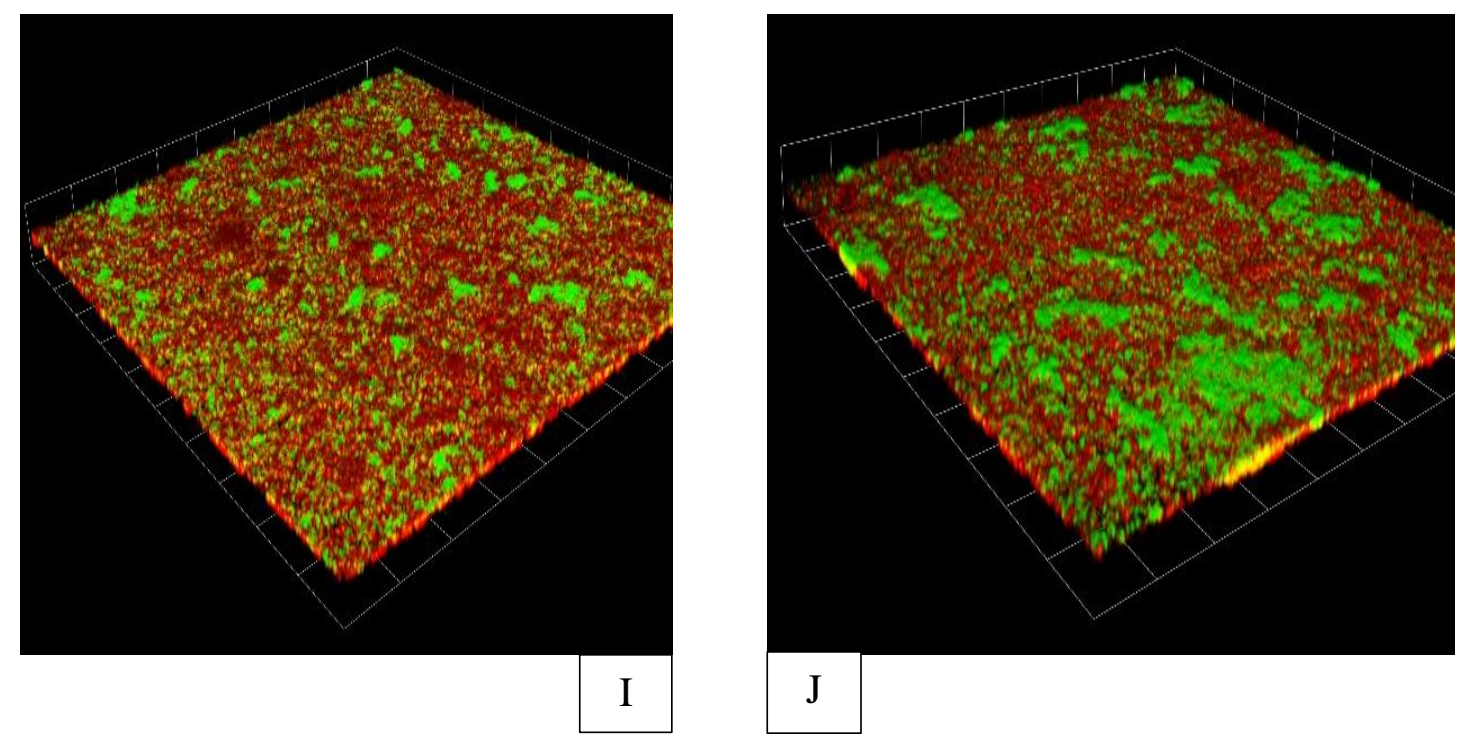

Fig. 4. Dual species community of $S$. gordonii and $P$. gingivalis at different optical densities

Confocal laser scanning analysis of heterotypic communities of $S$. gordonii (red) and $P$. gingivalis (green).

(A). S. gordonii at O.D 0.5. (B). S. gordonii at O.D 0.8. (C). S. gordonii at O.D 0.5 and $P$. gingivalis at O.D 0.2. (D). S. gordonii at O.D 0.5 and $P$. gingivalis at O.D 0.1. (E). S. gordonii at O.D 0.5 and P. gingivalis at O.D 0.05 (F). S. gordonii at O.D 0.5 and P. gingivalis at O.D 0.02 (G). S. gordonii at O.D 0.8 and $P$. gingivalis at O.D 0.05. (H). S. gordonii at O.D 0.8 and P. gingivalis at O.D 0.1. (I). S. gordonii at O.D 0.8 and P. gingivalis at O.D 0.5. (J). S. gordonii at O.D 0.8 and $P$. gingivalis at O.D 0.8 . 
Once the optimal conditions were established, the dual species biofilms were tested with the BAR peptide and the peptide analogs $1 . \mathrm{C}_{1-24} \mathrm{R}_{1182} \mathrm{I}_{1185} \mathrm{BAR}, 2 . \mathrm{R}_{1182} \mathrm{I}_{1185} \mathrm{BAR}$ and 3. $\mathrm{C}_{1-24} \mathrm{BAR}$ at concentrations of $1 \mu \mathrm{g} / \mathrm{ml}, 5 \mu \mathrm{g} / \mathrm{ml}$ and $10 \mu \mathrm{g} / \mathrm{ml}$ as described in the previous chapter. Previous studies showed that BAR peptide significantly inhibited $P$. gingivalis biofilm formation at a concentration of $10 \mu \mathrm{g} / \mathrm{ml}$. So we chose the concentrations of $1 \mu \mathrm{g} / \mathrm{ml}, 5 \mu \mathrm{g} / \mathrm{ml}$ and $10 \mu \mathrm{g} / \mathrm{ml}$ to determine if the structurally modified BAR peptide analogs showed potent inhibition compared to BAR peptide at a concentration of either $10 \mu \mathrm{g} / \mathrm{ml}$ or lesser.

Initially the BAR peptide was tested at concentrations $1 \mu \mathrm{g} / \mathrm{ml}, 5 \mu \mathrm{g} / \mathrm{ml}$ and $10 \mu \mathrm{g} / \mathrm{ml}$ and it's inhibitory activity was compared with control biofilm which was formed using $S$. gordonii cells at an optical density of 0.8 and $P$. gingivalis cells with an optical density of 0.1. The population of the individual bacteria were measured by the volocity software from the images formed by the confocal laser scanning microscopy. The BAR peptide inhibited the $P$. gingivalis micro colonies development on the $S$. gordonii substratum effectively at a concentration of $10 \mu \mathrm{g} / \mathrm{ml}$ as shown in Table1.

Subsequently the BAR peptide analogs $1 . \mathrm{C}_{1-24} \mathrm{R}_{1182} \mathrm{I}_{1185} \mathrm{BAR}, 2 . \mathrm{R}_{1182} \mathrm{I}_{1185} \mathrm{BAR}$ and 3. $\mathrm{C}_{1-24} \mathrm{BAR}$ and the BAR peptide were tested at concentrations $1 \mu \mathrm{g} / \mathrm{ml}, 5 \mu \mathrm{g} / \mathrm{ml}$ and $10 \mu \mathrm{g} / \mathrm{ml}$. The inhibitory activity of the peptide analogs was directly compared to the inhibitory activity of the BAR peptide and the control as shown in Fig. 5 and Fig. 6. 


\section{BAR Peptide}

Pre-incubation of $P$. gingivalis with $1 \mu \mathrm{g} / \mathrm{ml}$ of BAR peptide did not show much inhibition of $P$. gingivalis micro colonies. It exhibited only $4 \%$ of inhibition of $P$. gingivalis microcolonies. At $5 \mu \mathrm{g} / \mathrm{ml}$ BAR peptide showed $20 \%$ of inhibition of $P$. gingivalis microcolonies. Though BAR peptide did not exhibit significant inhibition at $1 \mu \mathrm{g} / \mathrm{ml}$ and $5 \mu \mathrm{g} / \mathrm{ml}$ concentrations, at $10 \mu \mathrm{g}$ per $\mathrm{ml}$ BAR peptide showed $77 \%$ of inhibition suggesting that the peptide competitively inhibited the $P$. gingivalis microcolony formation on $S$. gordonii substratum. Thus, a soluble synthetic 27 -mer peptide representing the adherence-promoting region of $\mathrm{SspB}$ effectively competes with the intact 170-kDa streptococcal cell surface protein for the P. gingivalis short fimbrial protein Mfa1 ${ }^{37}$.

The rate of inhibition by the BAR peptide on $P$. gingivalis adherence to $S$. gordonii is shown in (Fig. 5), TABLE (1) and (2). 


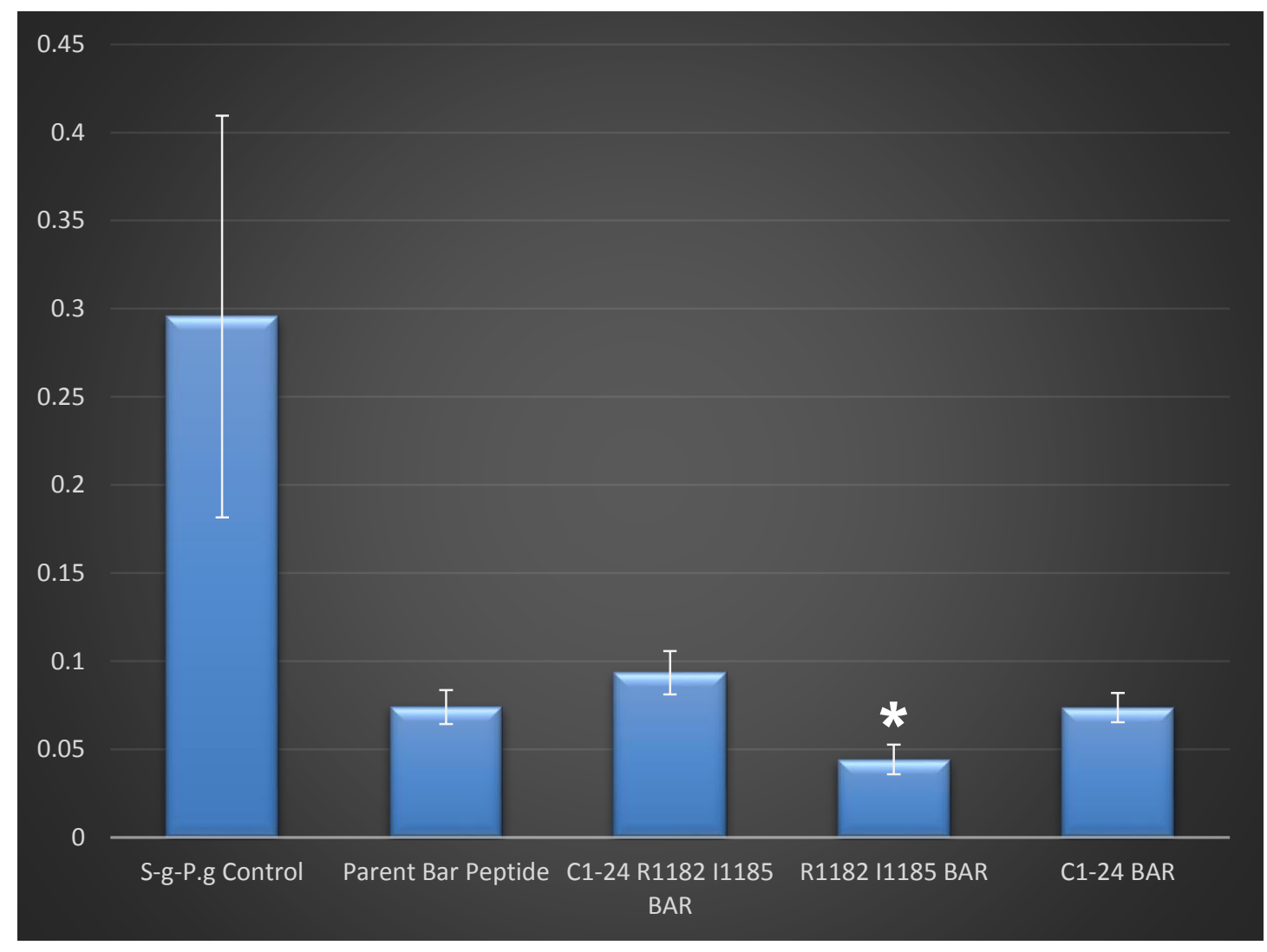

Fig. 5. Effectiveness of BAR peptide and BAR peptide analogs at $10 \mu \mathrm{g} / \mathrm{ml}$ on Streptococcus gordonii and Porphyromonas gingivalis dual species biofilm formation

Dose response of BAR peptide and its analogs $\mathrm{C}_{1-24} \mathrm{R}_{1182} \mathrm{I}_{1185} \mathrm{BAR}, \mathrm{R}_{1182} \mathrm{I}_{1185} \mathrm{BAR}$, $\mathrm{C}_{1-24} \mathrm{BAR}$ at $10 \mu \mathrm{g} / \mathrm{ml}$ concentration. The data acquired was analyzed and statistical difference in the rate of inhibition of $P$. gingivalis- $S$. gordonii interaction by BAR peptide and its analogs was determined by Anova followed by post-hoc t-tests using Microsoft excel Analysis Toolpak. When the rate of inhibition of $P$. gingivalis- $S$. gordonii interaction by BAR peptide analogs was compared with BAR peptide, the rate of inhibition by $\mathrm{R}_{1182} \mathrm{I}_{1185}$ BAR was statistically greater when compared to the BAR peptide $(\mathrm{p}<0.005)$ 
TABLE 1. Dose Response of BAR Peptide and its Analogs in P. gingivalis- $S$. gordonii Dual Species Biofilm

\begin{tabular}{|c|c|c|c|c|}
\hline & Control & $1 \mu \mathrm{g} / \mathrm{ml}$ & $5 \mu \mathrm{g} / \mathrm{ml}$ & $10 \mu \mathrm{g} / \mathrm{ml}$ \\
\hline Parent BAR & $0 \%$ & $4 \%$ & $20 \%$ & $77 \%$ \\
\hline $\begin{array}{l}\mathrm{C}_{1-24} \mathbf{R}_{1182} \\
\mathrm{I}_{1185} \mathrm{BAR}\end{array}$ & $0 \%$ & $6 \%$ & $27 \%$ & $70 \%$ \\
\hline $\begin{array}{c}\text { R1182I1185 } \\
\text { BAR }\end{array}$ & $0 \%$ & $44 \%$ & $62 \%$ & $87 \%$ \\
\hline $\mathrm{C}_{1-24} \mathrm{BAR}$ & $0 \%$ & $22 \%$ & $42 \%$ & $77 \%$ \\
\hline
\end{tabular}


TABLE 2. Percentage of inhibition of $P$. gingivalis- $S$. gordonii interaction by BAR peptide and its analogs at $10 \mu \mathrm{g} / \mathrm{ml}$

\begin{tabular}{|c|c|c|}
\hline & $\begin{array}{c}\text { Average or Mean of } \\
\text { P.g / S.g Volume } \\
\text { 土 Standard Deviation }\end{array}$ & $\begin{array}{c}\text { Percentage of } \\
\text { Inhibition }\end{array}$ \\
\hline Control & $0.3 \pm 0.1$ & $0 \%$ \\
\hline Parent BAR $10 \mu \mathrm{g} / \mathrm{ml}$ & $0.07 \pm 0.01$ & $77 \%$ \\
\hline $\begin{array}{c}\mathrm{C}_{1-24} \mathrm{R}_{1182} \mathrm{I}_{1185} \mathrm{BAR} \\
10 \mu \mathrm{g} / \mathrm{ml}\end{array}$ & $0.09 \pm 0.01$ & $70 \%$ \\
\hline $\begin{array}{c}\mathrm{R}_{1182} \mathrm{I}_{1185} \mathrm{BAR} \\
10 \mu \mathrm{g} / \mathrm{ml}\end{array}$ & $0.04 \pm 0.008$ & $87 \%$ \\
\hline $\mathrm{C}_{1-24}$ BAR $10 \mu \mathrm{g} / \mathrm{ml}$ & $0.07 \pm 0.008$ & $77 \%$ \\
\hline
\end{tabular}


The BAR peptide analogs were also tested at $1 \mu \mathrm{g} / \mathrm{ml}, 5 \mu \mathrm{g} / \mathrm{ml}$ and $10 \mu \mathrm{g} / \mathrm{ml}$ concentrations. BAR peptide and its analogs showed significant inhibition at $10 \mu \mathrm{g} / \mathrm{ml}$ concentration as shown in Table 1. and Table 2.

\section{$\mathrm{C}_{1-24} \mathbf{R}_{1182}$ 1185 $_{\text {BAR: }}$}

As described in Materials and methods the $\mathrm{C}_{1-24} \mathrm{R}_{1182} \mathrm{I}_{1185}$ BAR has cysteine molecules at positions 1167 and 1191 which forms a cyclic di-sulfide bond that aids in limiting bond rotations within the peptide backbone of the intervening active site NITVK sequence ${ }^{37}$. Arginine is a positively charged amino acid and Isoleucine is hydrophobic. Previous research studies have shown that peptides containing positively charged amino acids at position 1182 or hydrophobic residues at position 1185 bound $P$. gingivalis more effectively than did control peptides containing Asn and Val at these positions, suggesting that electrostatic and hydrophobic interactions may contribute to Mfa1-SspB binding ${ }^{37}$.

$\mathrm{C}_{1-24} \mathrm{R}_{1182} \mathrm{I}_{1185}$ BAR did not show much inhibition at $1 \mu \mathrm{g} / \mathrm{ml}$ concentration. It exhibited only $6 \%$ inhibition at this concentration (Fig. 7B.). At $5 \mu \mathrm{g} / \mathrm{ml}$ it exhibited $27 \%$ inhibition (Fig. 7C.) of $P$. gingivalis adherence to $S$. gordonii. Though at $1 \mu \mathrm{g} / \mathrm{ml}$ and $5 \mu \mathrm{g} / \mathrm{ml}$ concentration significant inhibition wasn't observed by $\mathrm{C}_{1-24} \mathrm{R}_{1182} \mathrm{I}_{1185}$ BAR, it exhibited $70 \%$ inhibition of $P$. gingivalis adherence on streptococcal substratum (Fig. 7D.) (Table1). The dose response by $\mathrm{C}_{1-24} \mathrm{R}_{1182} \mathrm{I}_{1185}$ is shown in Fig. 7E. 


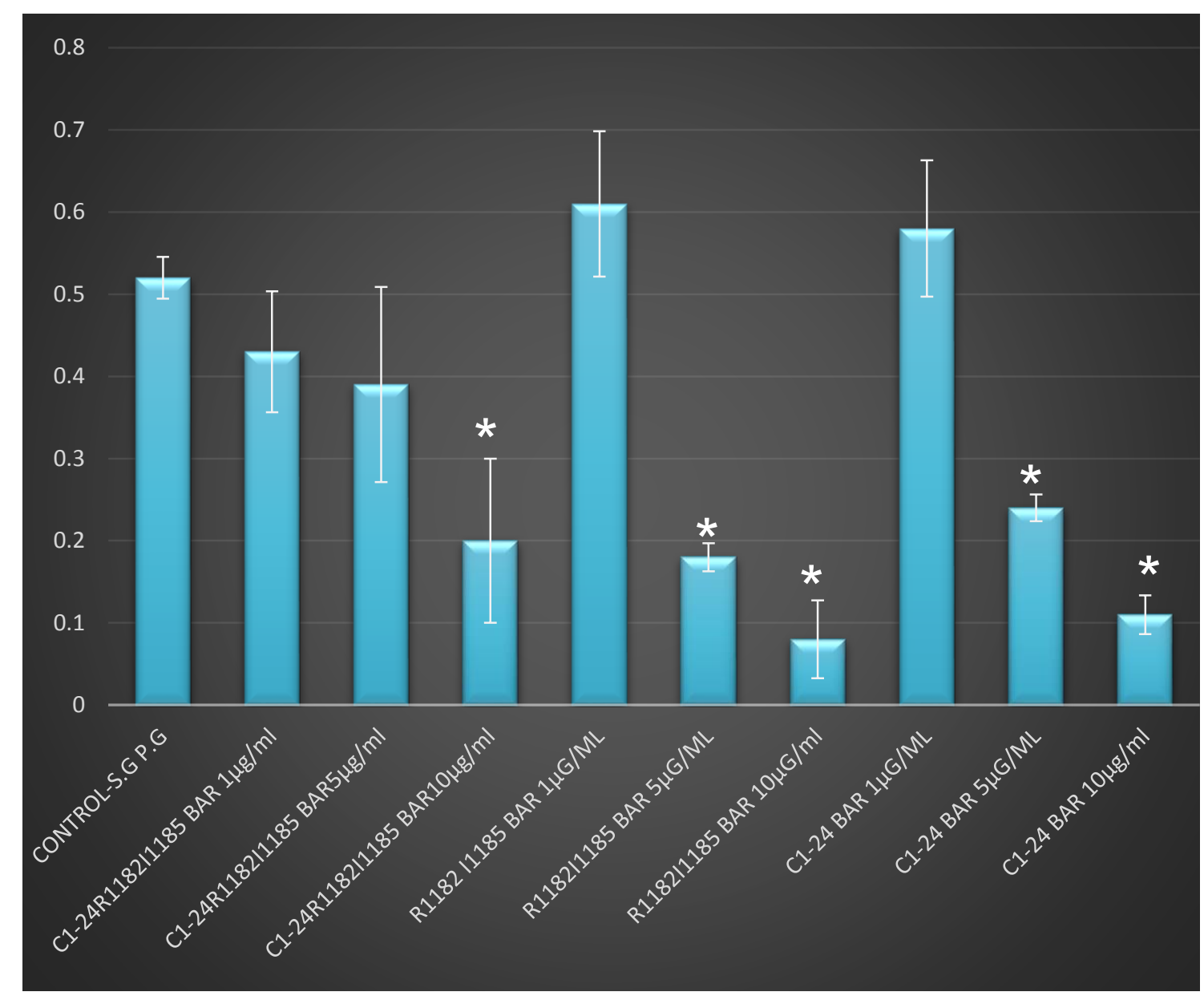

Fig. 6. Inhibition of $P$. gingivalis- $S$. gordonii dual species biofilm formation by BAR peptide analogs at $1 \mu \mathrm{g} / \mathrm{ml}, 5 \mu \mathrm{g} / \mathrm{ml}$, at $10 \mu \mathrm{g} / \mathrm{ml}$. The percentage of inhibition of $P$. gingivalis microcolony formation on $S$. gordonii substratum is calculated.

The BAR peptide analogs $\mathrm{C}_{1-24} \mathrm{R}_{1182} \mathrm{I}_{1185} \mathrm{BAR}$ at $10 \mu \mathrm{g} / \mathrm{ml}$ concentration, $\mathrm{R}_{1182} \mathrm{I}_{1185}$ BAR at $5 \mu \mathrm{g} / \mathrm{ml}$ and $10 \mu \mathrm{g} / \mathrm{ml}$ concentration and $\mathrm{C}_{1-24}$ BAR at $5 \mu \mathrm{g} / \mathrm{ml}$ and $10 \mu \mathrm{g} / \mathrm{ml}$ concentrations showed significant inhibition $(\mathrm{p}<0.001)$ compared to the control. 


\begin{tabular}{|c|c|}
\hline Figure. 7. & $\left.C_{1-24} R_{1182}\right|_{1185}$ BAR \\
\hline
\end{tabular}


Fig. 7. Effectiveness of $\mathrm{C}_{1-24} \mathrm{R}_{1182} \mathrm{I}_{1185}$ BAR in inhibition of $P$. gingivalis- $S$. gordonii interaction (A). S. gordonii-P. gingivalis dual species biofilm control. (B). Inhibition of $P$. gingivalis- $S$. gordonii interaction by $\mathrm{C}_{1-24} \mathrm{R}_{1182} \mathrm{I}_{1185} \mathrm{BAR}$ at $1 \mu \mathrm{g} / \mathrm{ml}$. (C). Inhibition of $P$. gingivalis- $S$. gordonii interaction by $\mathrm{C}_{1-24} \mathrm{R}_{1182} \mathrm{I}_{1185}$ BAR at $5 \mu \mathrm{g} / \mathrm{ml}$ (D) Inhibition of $P$. gingivalis- $S$. gordonii interaction by $\mathrm{C}_{1-}$ ${ }_{24} \mathrm{R}_{1182} \mathrm{I}_{1185} \mathrm{BAR}$ at $10 \mu \mathrm{g} / \mathrm{ml}$ concentration. 


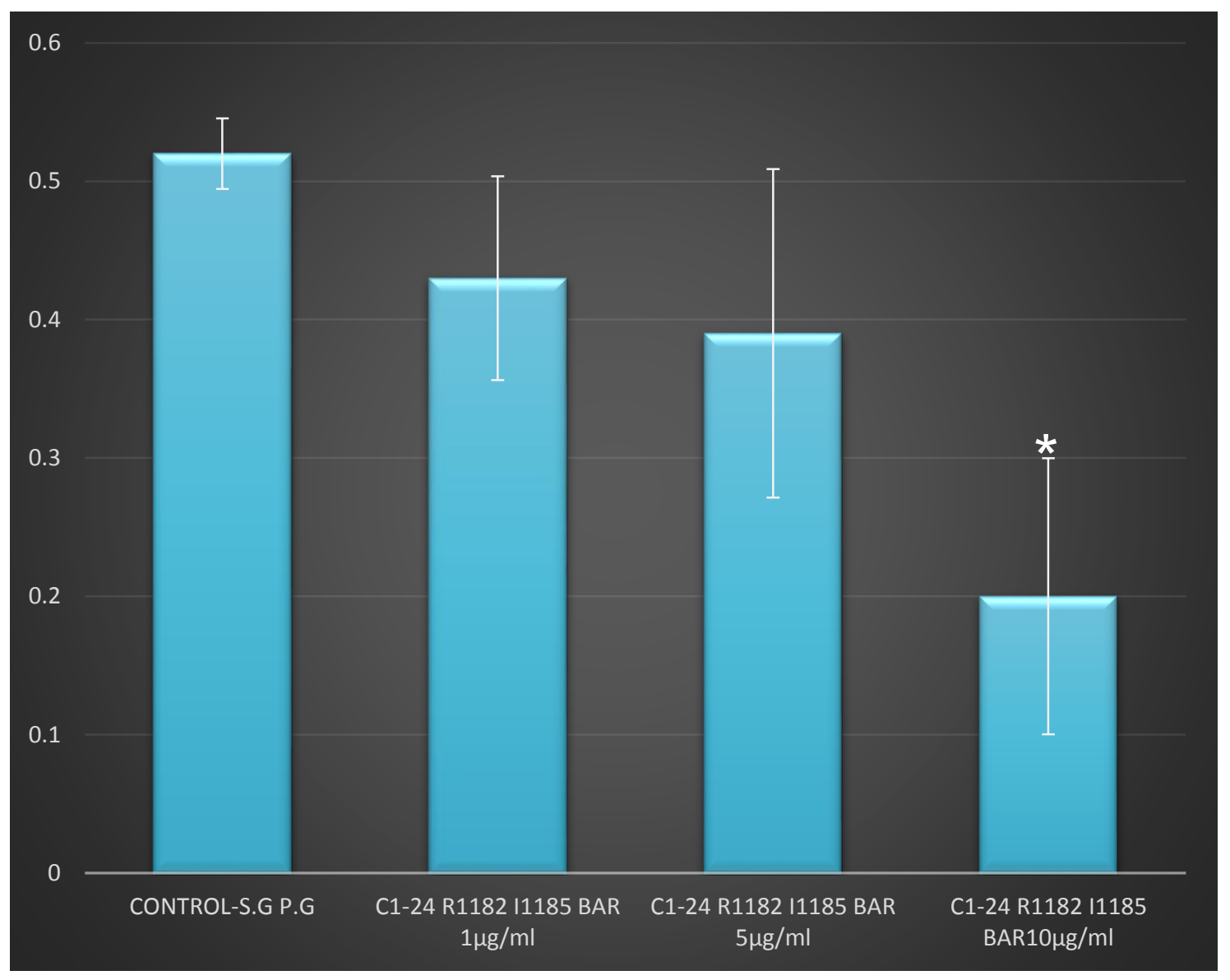

Fig. 7 (E). Dose response of $\mathrm{C}_{1-24} \mathrm{R}_{1182} \mathrm{I}_{1185} \mathrm{BAR}$ in inhibition of $P$. gingivalis microcolony formation on $S$. gordonii substrate. It showed a statistically significant inhibition $(\mathrm{p}<0.0004)$ at $10 \mu \mathrm{g} / \mathrm{ml}$ concentration when compared to the control. 


\section{R1182 $_{1185}$ BAR:}

This peptide analog has positively charged amino acid arginine at 1182 position and hydrophobic residue Isoleucine at 1185 position. The leucine molecules at positions 1167 and 1191 remain unchanged as in BAR peptide. This BAR peptide analog showed competitive inhibition of $P$. gingivalis micro colonies on $S$. gordonii at $10 \mu \mathrm{g} / \mathrm{ml}$ concentration when compared to the inhibition by BAR peptide at $10 \mu \mathrm{g} / \mathrm{ml}$ as shown in Table1.

$\mathrm{R}_{1182} \mathrm{I}_{1185}$ BAR showed $44 \%$ inhibition at $1 \mu \mathrm{g} / \mathrm{ml}$ concentration (Fig. 8B) and 62\% inhibition of the $P$. gingivalis adherence to $S$. gordonii at $5 \mu \mathrm{g} / \mathrm{ml}$ concentration (Fig. 8C). At $10 \mu \mathrm{g} / \mathrm{ml}$ concentration it showed $87 \%$ of inhibition of $P$. gingivalis micro colonies on S. gordonii substratum as shown in (Fig 8D.) and Table1.

The dose response of $\mathrm{R}_{1182} \mathrm{I}_{1185} \mathrm{BAR}$ is as shown in (Fig. 8E). 


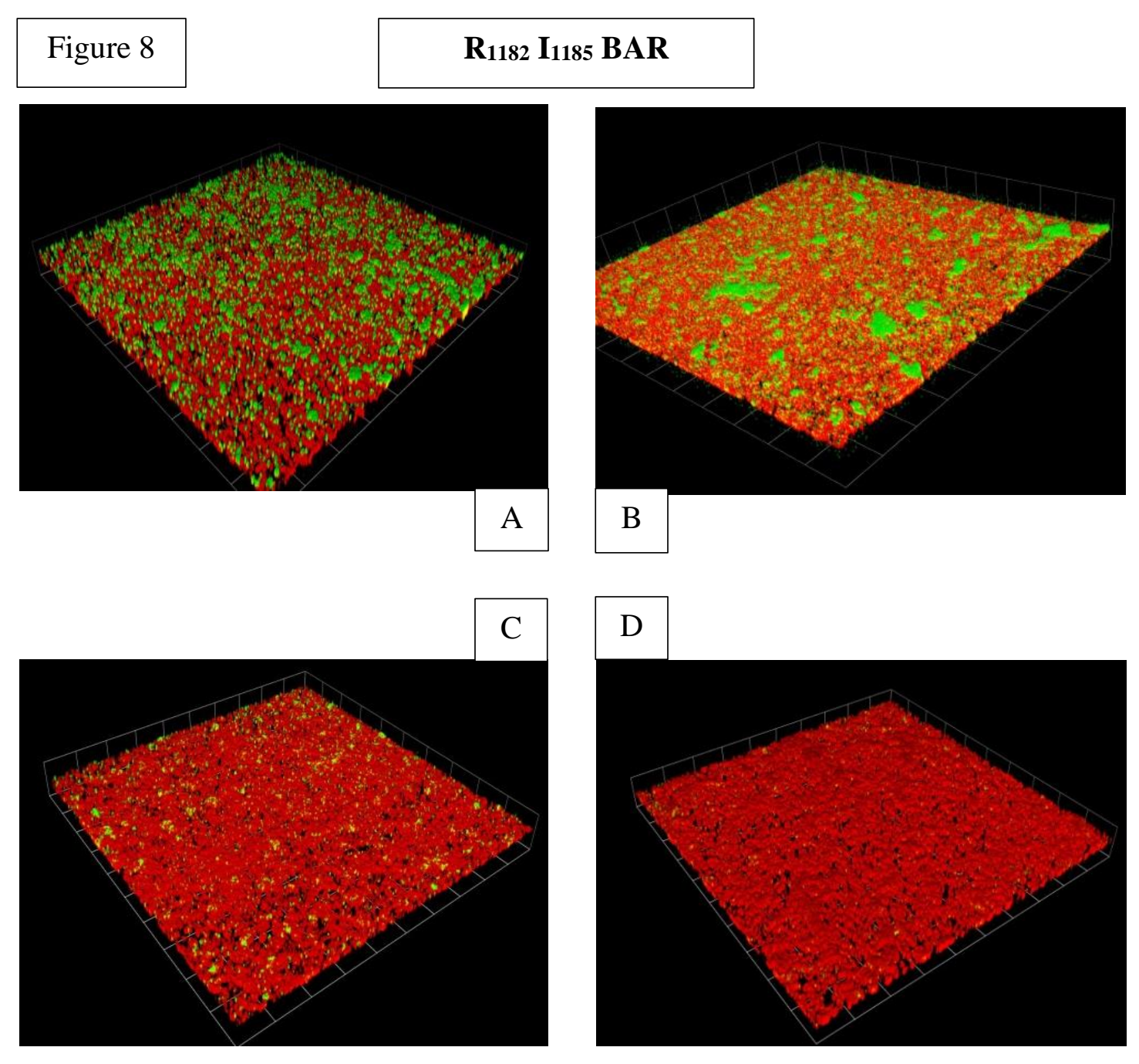

Fig. 8. Effectiveness of $\mathrm{R}_{1182} \mathrm{I}_{1185} \mathrm{BAR}$ in inhibition of $P$. gingivalis- $S$. gordonii interaction. (A). S. gordonii - P. gingivalis dual species biofilm control. (B). Inhibition of $P$. gingivalis- $S$. gordonii interaction by $\mathrm{R}_{1182} \mathrm{I}_{1185}$ BAR at $1 \mu \mathrm{g} / \mathrm{ml}$. (C). Inhibition of $P$. gingivalis- $S$. gordonii interaction by $\mathrm{R}_{1182} \mathrm{I}_{1185}$ BAR at $5 \mu \mathrm{g} / \mathrm{ml}$ (D) Inhibition of $P$. gingivalis- $S$. gordonii interaction by $\mathrm{R}_{1182} \mathrm{I}_{1185} \mathrm{BAR}$ at $10 \mu \mathrm{g} / \mathrm{ml}$ concentration. 


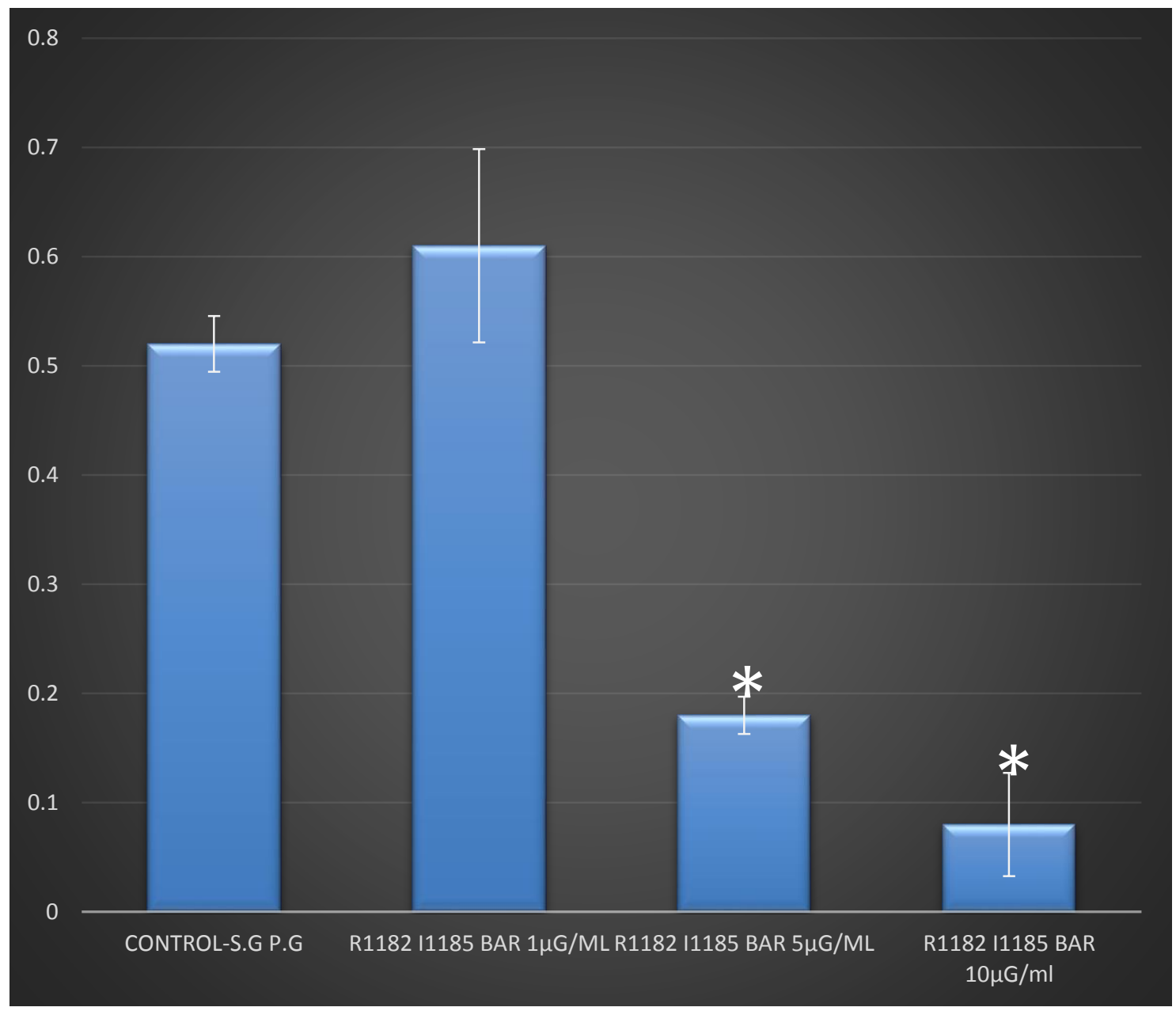

Fig. 8. (E). Dose response of $\mathrm{R}_{1182} \mathrm{I}_{1185} \mathrm{BAR}$ in inhibition of $P$. gingivalis microcolony formation on $S$. gordonii substrate. It showed a statistically significant inhibition $(\mathrm{p}<$ $0.001)$ at $5 \mu \mathrm{g} / \mathrm{ml}$ and $10 \mu \mathrm{g} / \mathrm{ml}$ concentration when compared to the control. 


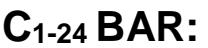

This peptide analog consists of cysteine molecules at positions 1167 and 1191 which form cyclic di-sulfide bond that limits bond rotation within peptide backbone. It contains Asparginine at position 1182 and Valine at position 1185 as in BAR peptide.

$\mathrm{C}_{1-24} \mathrm{BAR}$ showed $22 \%$ inhibition at $1 \mu \mathrm{g} / \mathrm{ml}$ concentration (Fig 9B) and $42 \%$ inhibition rate at $5 \mu \mathrm{g} / \mathrm{ml}$ (Fig. 9C.) concentration. It exhibited $77 \%$ of inhibition at $10 \mu \mathrm{g} / \mathrm{ml}$ (Fig. 9D.) concentration as shown in Table1. The dose response of $\mathrm{C}_{1-24} \mathrm{BAR}$ is as shown in Fig. 9E

At a concentration of $10 \mu \mathrm{g} / \mathrm{ml}$ the inhibitory activity of the BAR peptide and its analogs $\mathrm{C}_{1-24} \mathrm{R}_{1182} \mathrm{I}_{1185} \mathrm{BAR}, \mathrm{R}_{1182} \mathrm{I}_{1185} \mathrm{BAR}$ and $\mathrm{C}_{1-24} \mathrm{BAR}$ was significant compared to the control (Fig. 5. And Fig. 6). In specific the inhibitory activity of $\mathrm{R}_{1182} \mathrm{I}_{1185}$ BAR was statistically greater when compared to the BAR peptide and the other structurally modified BAR peptides- $\mathrm{C}_{1-24} \mathrm{R}_{1182} \mathrm{I}_{1185} \mathrm{BAR}$ and $\mathrm{C}_{1-24} \mathrm{BAR}$. Its rate of inhibition of the $P$. gingivalis - S. gordonii interaction was much higher when compared to the BAR peptide at $10 \mu \mathrm{g} / \mathrm{ml}$ concentration and therefore $\mathrm{R}_{1182} \mathrm{I}_{1185} \mathrm{BAR}$ is a more potent inhibitor of the $P$. gingivalis- S. gordonii dual species biofilm formation compared to BAR peptide.

All the experiments were done in triplicate for 3-4 times to ensure that the results were consistent. 




Fig. 9. Effectiveness of $\mathrm{C}_{1-24} \mathrm{BAR}$ in inhibition of $P$. gingivalis- $S$. gordonii interaction

(A). $\quad$ S. gordonii $-P$. gingivalis dual species biofilm control. (B). Inhibition of $P$. gingivalis- $S$. gordonii interaction by $\mathrm{C}_{1-24} \mathrm{BAR}$ at $1 \mu \mathrm{g} / \mathrm{ml}$. (C). Inhibition of $P$. gingivalis- $S$. gordonii interaction by $\mathrm{C}_{1-24} \mathrm{BAR}$ at $5 \mu \mathrm{g} / \mathrm{ml}$ (D). Inhibition of $P$. gingivalis- $S$. gordonii interaction by $\mathrm{C}_{1-24} \mathrm{BAR}$ at $10 \mu \mathrm{g} / \mathrm{ml}$ concentration. 


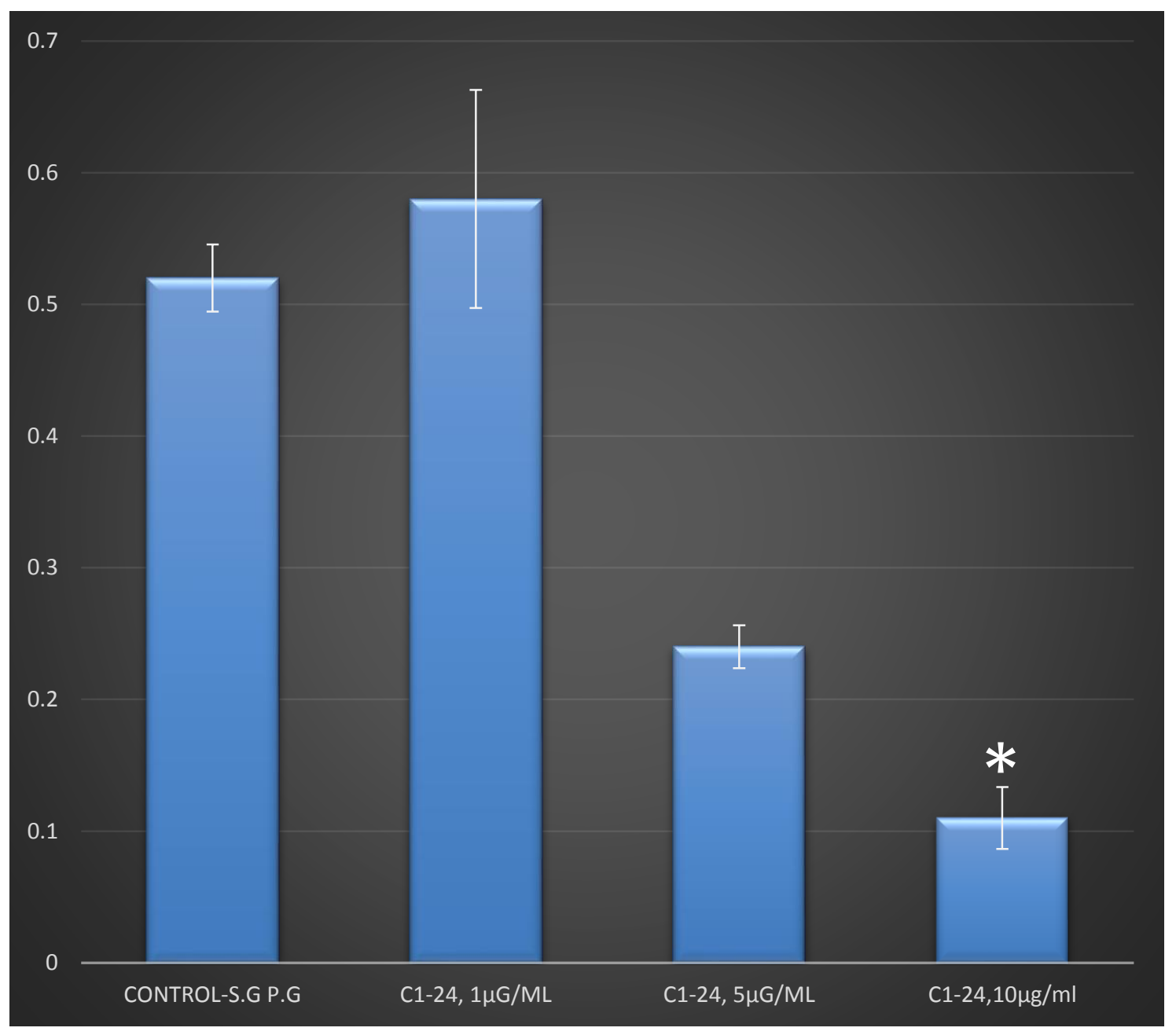

Fig. 9. (E). Dose response of $\mathrm{C}_{1-24} \mathrm{BAR}$ in inhibition of $P$. gingivalis microcolony formation on $S$. gordonii substrate. It showed a statistically significant inhibition $(\mathrm{p}<0.001)$ at $5 \mu \mathrm{g} / \mathrm{ml}$ and $10 \mu \mathrm{g} / \mathrm{ml}$ concentration when compared to the control. 


\section{Three Species biofilm:}

Once the efficiency of the structurally modified BAR peptides in inhibiting the $P$. gingivalis- S. gordonii dual species biofilm formation was established, we then tested the efficiency of the BAR peptide and the structurally modified BAR peptides $\mathrm{C}_{1-24} \mathrm{R}_{1182} \mathrm{I}_{1185}$ BAR, $\mathrm{R}_{1182} \mathrm{I}_{1185} \mathrm{BAR}$ and $\mathrm{C}_{1-24} \mathrm{BAR}$ in a multi species biofilm which was a three species complex biofilm. P. gingivalis, S. gordonii and F. nucleatum were the three species that were used in the complex biofilm formation.

Our initial experiments were focused on establishing optimum inocula for $P$. gingivalis, S. gordonii and F. nucleatum to reproducibly generate three species complex biofilms for testing the inhibitory activity of BAR peptide and BAR peptide analogs. To achieve this, three species biofilms were formed at different optical densities and compared. The optimum conditions were found to use an optical density of 0.8 for Streptococcus gordonii, 0.2 for $P$. gingivalis and 2.0 for Fusobacterium nucleatum. S. gordonii formed a uniform confluent layer at optical density 0.8. P. gingivalis showed a uniform distribution and distinct micro colony formation at an optical density of 0.2 on $S$.

gordonii. F. nucleatum at an optical density of 2.0 formed thick complex biofilms with $S$. gordonii and $P$. gingivalis.

Streptococcus gordonii was labeled with hexidium iodide, Porphyromonas gingivalis was labeled with 5- (6) Carboxy fluorescein - succinyl ester and Fusobacterium nucleatum was labeled with DDAO-SE. Texas RED, FITC and CY5 were the fluorescent dyes assigned to the labeled bacterial cells while imaging using confocal laser scanning microscopy. 
Once the optical densities were established, three species biofilms were formed and the BAR peptide was tested at concentrations $1 \mu \mathrm{g} / \mathrm{ml}, 5 \mu \mathrm{g} / \mathrm{ml}, 10 \mu \mathrm{g} / \mathrm{ml}, 25 \mu \mathrm{g} / \mathrm{ml}$ and $50 \mu \mathrm{g} / \mathrm{ml}$. The inhibitory activity was compared with $S$. gordonii, $P$. gingivalis and $F$. nucleatum three species biofilm control. At $1 \mu \mathrm{g} / \mathrm{ml}, 5 \mu \mathrm{g} / \mathrm{ml}$ and $10 \mu \mathrm{g} / \mathrm{ml}-$ BAR peptide did not exhibit any significant inhibitory activity in relation to the three species biofilm. Though BAR peptide and its analogs did not show significant inhibition at $1 \mu \mathrm{g} / \mathrm{ml}$ and $5 \mu \mathrm{g} / \mathrm{ml}$ concentration they showed competitive inhibition at $10 \mu \mathrm{g} / \mathrm{ml}$ in dual species biofilms. This indicates that BAR peptide and its analogs were not as effective as in Dual species biofilm at $10 \mu \mathrm{g} / \mathrm{ml}$ concentration in a three species complex biofilm.

So therefore we tested the BAR peptide and the three peptide analogs- 1. C1-24 R1182 $\mathrm{I}_{1185} \mathrm{BAR}, 2 . \mathrm{R}_{1182 \mathrm{I} 1185} \mathrm{BAR}$ and 3. $\mathrm{C}_{1-24} \mathrm{BAR}$ at $10 \mu \mathrm{g} / \mathrm{ml}, 25 \mu \mathrm{g} / \mathrm{ml}$ and $50 \mu \mathrm{g} / \mathrm{ml}$ concentrations. The inhibitory activity was compared directly to the three species biofilm control. The population of each individual bacteria are measured by the Volocity software based on the fluorescent dyes they were labeled with from the images that were formed using confocal laser scanning microscopy.

An interesting observation that was seen in these experiments was that there was a reduction in $F$. nucleatum values as the $P$. gingivalis Mfa1- $S$. gordonii SspB interaction was inhibited by the BAR peptide and the BAR peptide analogs. This might be due to the strong synergism present between $P$. gingivalis and $F$. nucleatum. 


\section{BAR Peptide}

Pre-incubation of $P$. gingivalis with $10 \mu \mathrm{g} / \mathrm{ml}$ of BAR peptide did not show much inhibition of $P$. gingivalis microcolonies (TABLE 3). It exhibited only $10.1 \%$ of inhibition of $P$. gingivalis microcolonies at $10 \mu \mathrm{g} / \mathrm{ml}$ (Fig. 10. B). At $25 \mu \mathrm{g} / \mathrm{ml}$ BAR peptide showed $28 \%$ of inhibition of $P$. gingivalis microcolonies. Though BAR peptide did not exhibit significant inhibition at $10 \mu \mathrm{g} / \mathrm{ml}$ and $25 \mu \mathrm{g} / \mathrm{ml}$ concentrations, at $50 \mu \mathrm{g}$ per ml BAR peptide showed $84.1 \%$ of inhibition (Fig. 10. C) suggesting that the peptide competitively inhibited the $P$. gingivalis microcolony formation on $S$. gordonii substratum at $50 \mu \mathrm{g} / \mathrm{ml}$ concentration. The rate of inhibition by the BAR peptide on $P$. gingivalis adherence to $S$. gordonii in a three species complex biofilm is shown in TABLE 3.

At a concentration of $10 \mu \mathrm{g} / \mathrm{ml}$ there was no reduction observed in $F$. nucleatum volume (Fig. 10B). At a concentration of $25 \mu \mathrm{g} / \mathrm{ml}$ of BAR peptide when $P$. gingivalis was reduced by $28 \%$ there was a $34 \%$ reduction in $F$. nucleatum volume. At $50 \mu \mathrm{g} / \mathrm{ml}$ concentration of BAR peptide when $P$. gingivalis was reduced by $84.1 \%$ there was a $78 \%$ reduction that was observed in F. nucleatum (Fig. 10C).

The dose response of BAR peptide and its analogs on $\mathrm{P}$. gingivalis adherence to $S$. gordonii are shown in Table 3 and percentage reduction in $F$. nucleatum volume due to the effect from the inhibition of $P$. gingivalis-S. gordonii interaction by the BAR peptide and its analogs is shown in Table4.

The BAR peptide analogs were also tested at $10 \mu \mathrm{g} / \mathrm{ml}, 25 \mu \mathrm{g} / \mathrm{ml}$ and $50 \mu \mathrm{g} / \mathrm{ml}$ concentrations. BAR peptide and its analogs showed significant inhibition at $50 \mu \mathrm{g} / \mathrm{ml}$ concentration as shown in Table3. 


\section{Figure. 10}

\section{BAR Peptide}
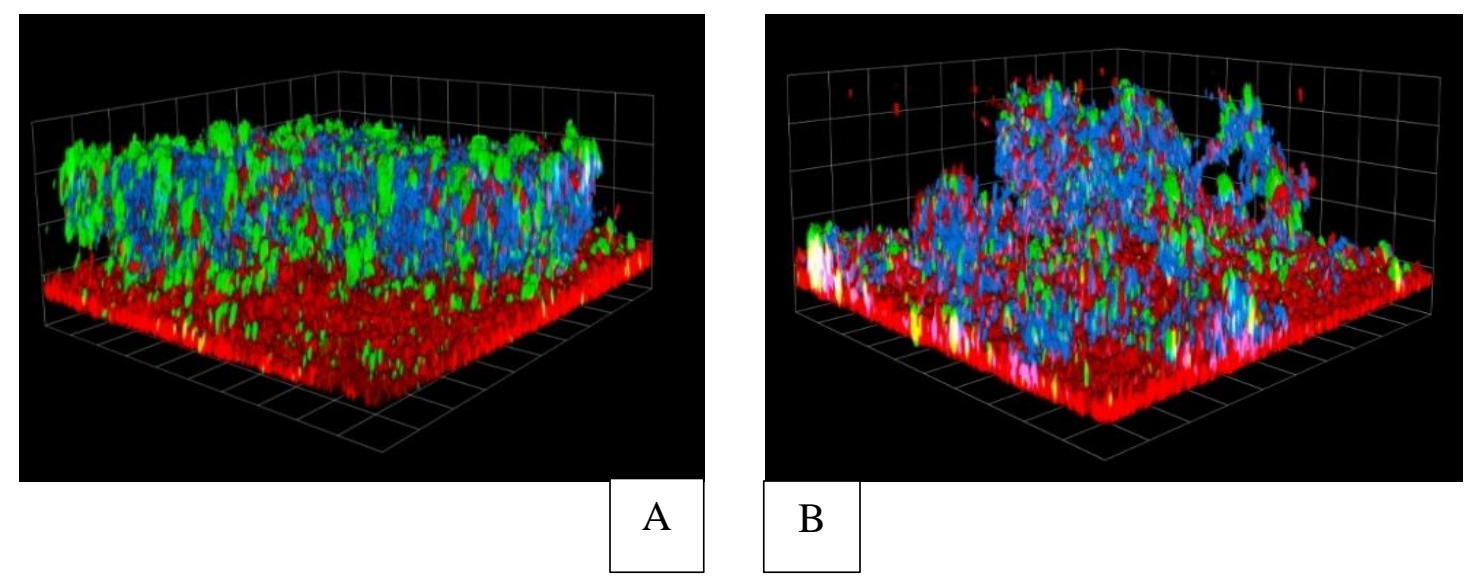

B

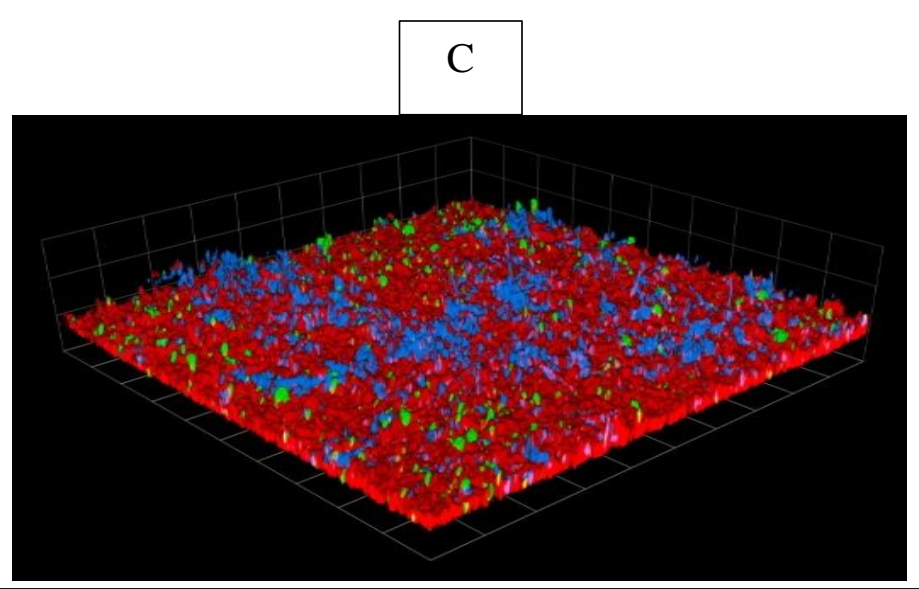

Fig. 10. Three species community of $S$. gordonii, $P$. gingivalis and $F$. nucleatum. Confocal laser scanning analysis of heterotypic communities of $S$. gordonii (red), $P$. gingivalis (green) and $F$. nucleatum (blue). Effectiveness of BAR peptide in inhibition of $P$. gingivalis- $S$. gordonii interaction in a three species biofilm. (A). $S$. gordonii-P. gingivalis three species biofilm control. (B). Inhibition of $P$. gingivalis$S$. gordonii interaction by BAR Peptide at $10 \mu \mathrm{g} / \mathrm{ml}$. (C). Inhibition of $P$. gingivalisS. gordonii interaction by BAR Peptide at $50 \mu \mathrm{g} / \mathrm{ml}$ in a three species biofilm. 


\section{$\mathbf{C}_{1-24} \mathbf{R}_{1182} \mathbf{l}_{1185}$ BAR:}

$\mathrm{C}_{1-24} \mathrm{R}_{1182} \mathrm{I}_{1185}$ BAR did not show inhibition of $P$. gingivalis at $10 \mu \mathrm{g} / \mathrm{ml}$ concentration (Fig. 11. B). At $25 \mu \mathrm{g} / \mathrm{ml}$ it exhibited $40 \%$ inhibition (Fig. 11. C) of P. gingivalis adherence to $S$. gordonii. Though at $25 \mu \mathrm{g} / \mathrm{ml}$ concentration significant inhibition wasn't observed by $\mathrm{C}_{1-24} \mathrm{R}_{1182} \mathrm{I}_{1185}$ BAR, it exhibited $87.5 \%$ inhibition of $P$. gingivalis adherence on streptococcal substratum at $50 \mu \mathrm{g} / \mathrm{ml}$ concentration (Fig. 11. D).

At $10 \mu \mathrm{g} / \mathrm{ml}$ concentration of $\mathrm{C}_{1-24} \mathrm{R}_{1182} \mathrm{I}_{1185} \mathrm{BAR}$ when $P$. gingivalis showed no reduction, there was no reduction observed even in F. nucleatum volume (Fig. 11. B). At $25 \mu \mathrm{g} / \mathrm{ml}$ concentration of $\mathrm{C}_{1-24} \mathrm{R}_{1182} \mathrm{I}_{1185} \mathrm{BAR}$ when $P$. gingivalis showed $40 \%$ inhibition (Fig. 11. C), there was a 59\% reduction observed even in F. nucleatum volume and at $50 \mu \mathrm{g} / \mathrm{ml}$ concentration (Fig. 11. D) of $\mathrm{C}_{1-24} \mathrm{R}_{1182} \mathrm{I}_{1185}$ BAR when there was an $87.5 \%$ inhibition of $P$. gingivalis, a reduction of $88.5 \%$ was observed in relation to $F$. nucleatum. 


\section{Figure. 11}

\section{$\mathrm{C}_{1-24} \mathrm{R}_{1182} \mathrm{I}_{1185} \mathrm{BAR}$}
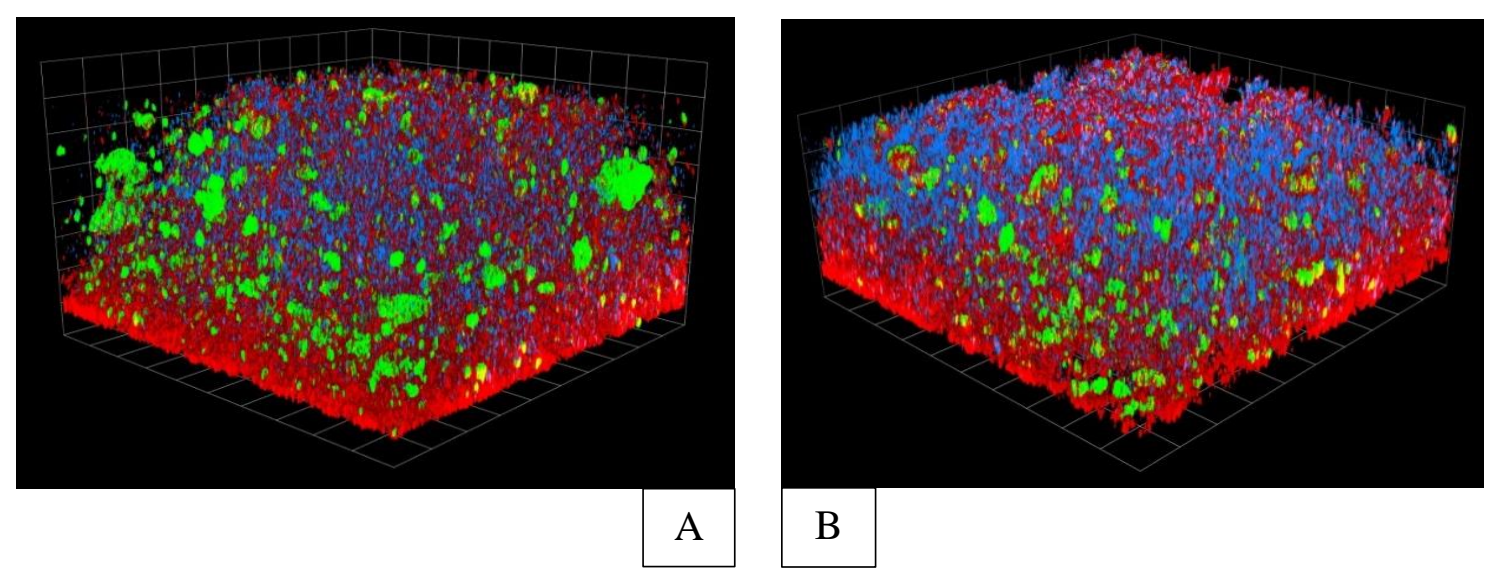

\section{B}
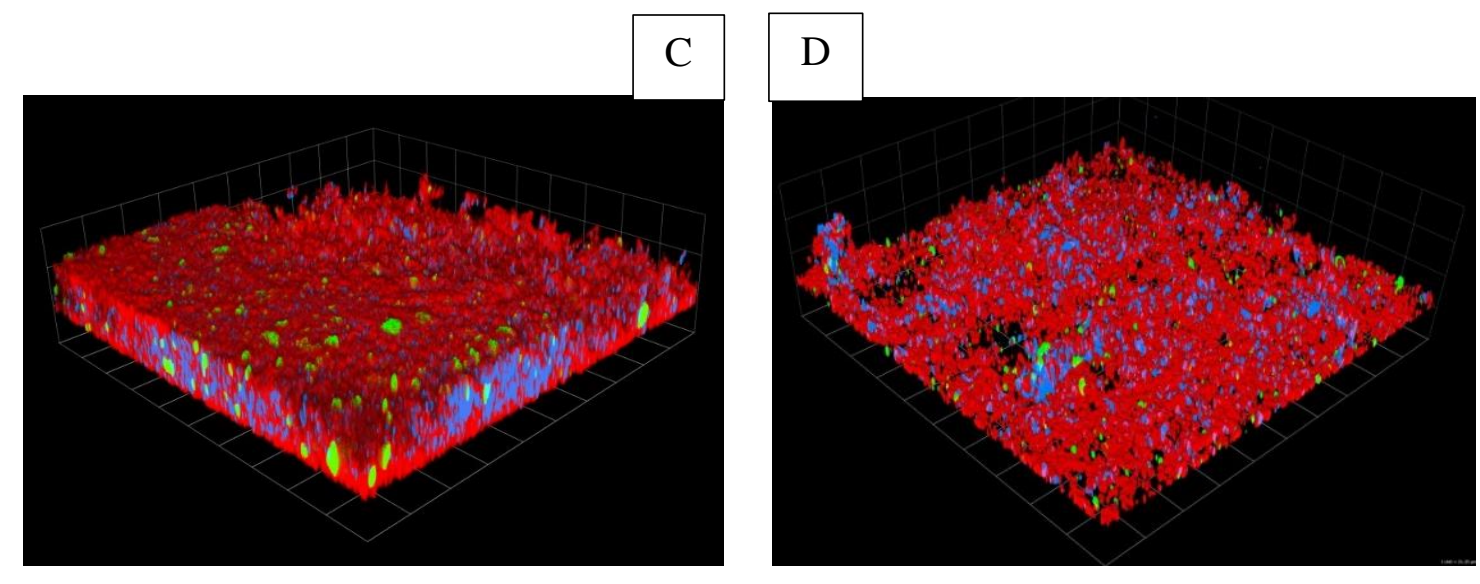

Fig. 11. Effectiveness of $\mathrm{C}_{1-24} \mathrm{R}_{1182} \mathrm{I}_{1185}$ BAR in inhibition of P. gingivalis- S. gordonii interaction in a three species biofilm.

(A). S. gordonii - P. gingivalis three species biofilm control. (B). Inhibition of $P$. gingivalis- $S$. gordonii interaction by $\mathrm{C}_{1-24} \mathrm{R}_{1182} \mathrm{I}_{1185} \mathrm{BAR}$ at $10 \mu \mathrm{g} / \mathrm{ml}$. (C). Inhibition of $P$. gingivalis- $S$. gordonii interaction by $\mathrm{C}_{1-24} \mathrm{R}_{1182} \mathrm{I}_{1185}$ BAR at $25 \mu \mathrm{g} / \mathrm{ml}$ (D). Inhibition of $P$. gingivalis- $S$. gordonii interaction by $\mathrm{C}_{1-24} \mathrm{R}_{1182} \mathrm{I}_{1185} \mathrm{BAR}$ at $50 \mu \mathrm{g} / \mathrm{ml}$ concentration. 


\section{R1182 $_{1185}$ BAR:}

This peptide analog has positively charged amino acid arginine at 1182 position and hydrophobic residue Isoleucine at 1185 position. $\mathrm{R}_{1182} \mathrm{I}_{1185} \mathrm{BAR}$ showed $68 \%$ inhibition at $10 \mu \mathrm{g} / \mathrm{ml}$ concentration (Fig. 12B) and $72.3 \%$ inhibition of the $P$. gingivalis adherence to S. gordonii at $25 \mu \mathrm{g} / \mathrm{ml}$ concentration (Fig. $12 \mathrm{C}$ ). At $50 \mu \mathrm{g} / \mathrm{ml}$ concentration it showed $88 \%$

of inhibition of $P$. gingivalis microcolonies on $S$. gordonii substratum as shown in (Fig 12D).

At $10 \mu \mathrm{g} / \mathrm{ml}$ concentration of R1182I1185 BAR when P. gingivalis showed $68 \%$ reduction, there was $1.5 \%$ reduction observed in $F$. nucleatum volume (Fig. 12B). At $25 \mu \mathrm{g} / \mathrm{ml}$ concentration of $\mathrm{R}_{1182} \mathrm{I}_{1185}$ BAR when $P$. gingivalis showed $72.3 \%$ inhibition, there was a $63.5 \%$ reduction observed in F. nucleatum volume (Fig. 12C) and at $50 \mu \mathrm{g} / \mathrm{ml}$ concentration of $\mathrm{C}_{1-24} \mathrm{R}_{1182} \mathrm{I}_{1185} \mathrm{BAR}$ when there was an $88 \%$ inhibition of $P$. gingivalis, a reduction of $85.1 \%$ was observed in relation to F. nucleatum (Fig. 12D). 


\section{Figure 12}
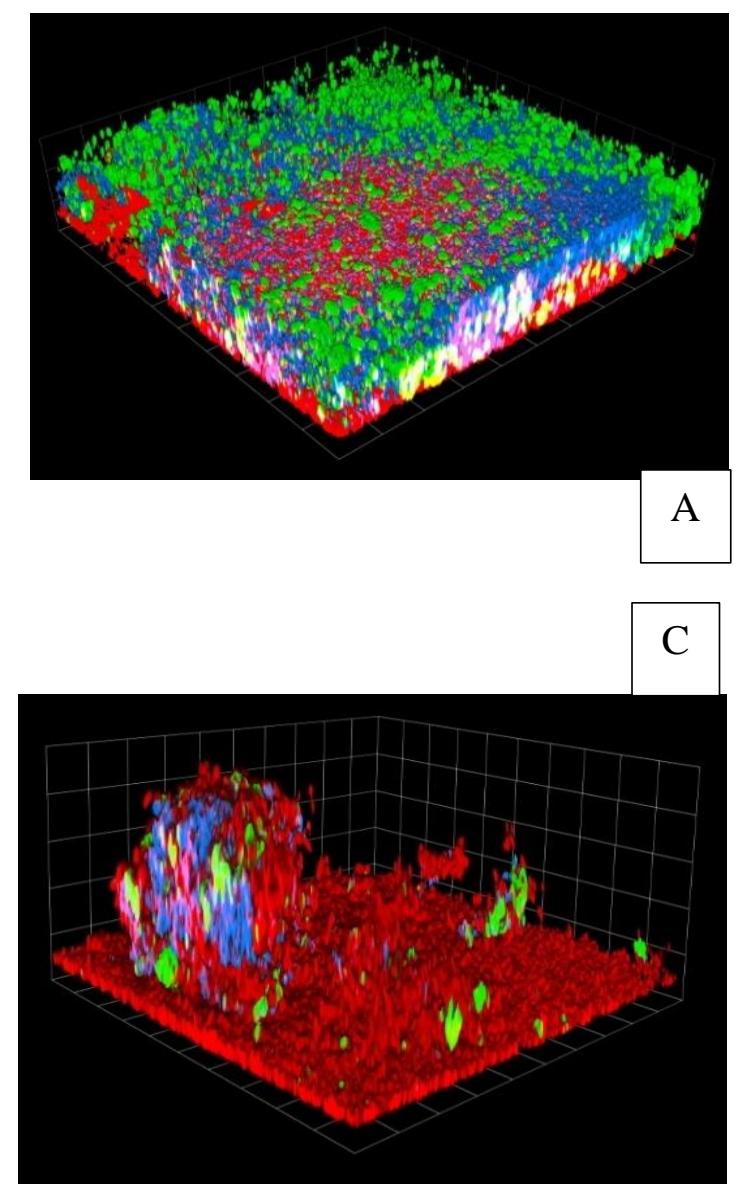

\section{$\mathbf{R}_{1182} \mathbf{l}_{1185}$ BAR}

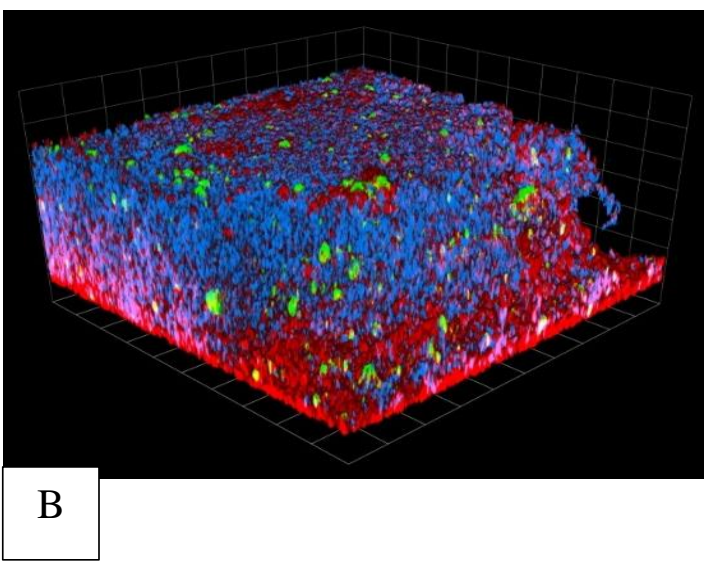

$\mathrm{D}$

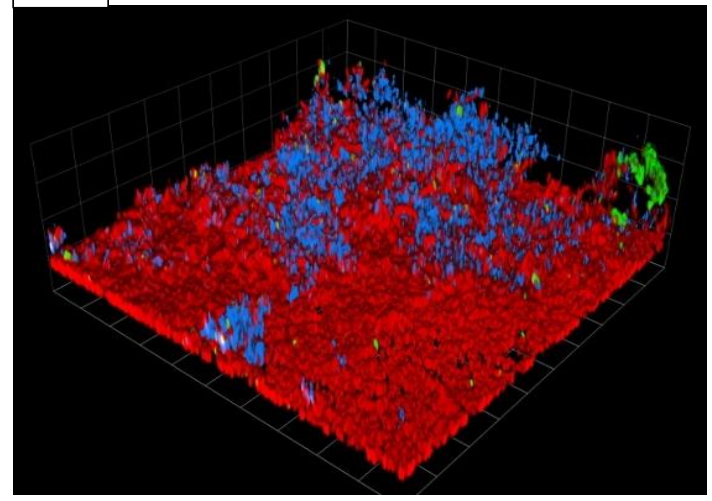

Fig. 12. Effectiveness of $\mathrm{R}_{1182} \mathrm{I}_{1185}$ BAR in inhibition of $P$. gingivalis- $S$. gordonii interaction in a three species biofilm.

(A). S. gordonii - $\quad P$. gingivalis three species biofilm control. (B). Inhibition of $P$. gingivalis- $S$. gordonii interaction by $\mathrm{R}_{1182} \mathrm{I}_{1185} \mathrm{BAR}$ at $10 \mu \mathrm{g} / \mathrm{ml}$. (C). Inhibition of $P$. gingivalis- S. gordonii interaction by $\mathrm{R}_{1182} \mathrm{I}_{1185} \mathrm{BAR}$ at $25 \mu \mathrm{g} / \mathrm{ml}$ (D). Inhibition of $P$. gingivalis- S. gordonii interaction by $\mathrm{R}_{1182} \mathrm{I}_{1185} \mathrm{BAR}$ at $50 \mu \mathrm{g} / \mathrm{ml}$ concentration. 


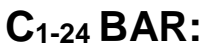

$\mathrm{C}_{1-24}$ BAR showed reduction in $S$. gordonii along with reduction in $P$. gingivalis and F. nucleatum as shown in figure. Because of the reduction in S. gordonii when P. gingivalis and $F$. nucleatum average volumes were calculated after normalizing average $S$. gordonii value to the average volume of the $S$. gordonii control to determine the percentage of inhibition, it did not give any reduction in the $P$. gingivalis and $F$. nucleatum values. The dose response of $\mathrm{C}_{1-24} \mathrm{BAR}$ is shown in Fig 13. B, Fig 13. C and Fig. 13. D 


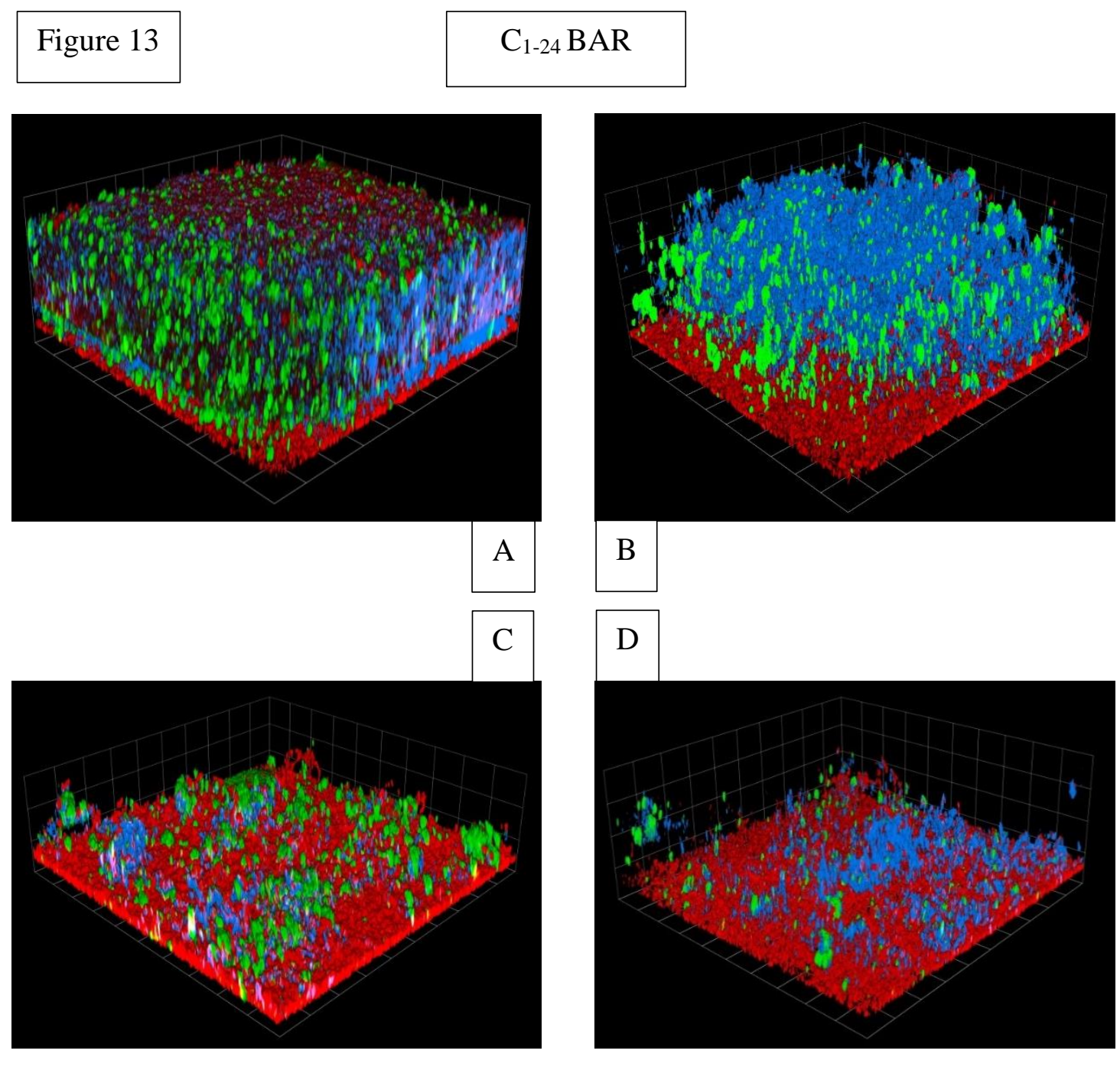

Fig. 13. Effectiveness of $\mathrm{C}_{1-24} \mathrm{BAR}$ in inhibition of $P$. gingivalis- $S$. gordonii interaction in a three species biofilm.

(A). S. $\quad$ gordonii $\quad-\quad P$. gingivalis three species biofilm control. (B). Inhibition of $P$. gingivalis- $S$. gordonii interaction by $\mathrm{C}_{1-24} \mathrm{BAR}$ at $10 \mu \mathrm{g} / \mathrm{ml}$. (C). Inhibition of $P$. gingivalis- $S$. gordonii interaction by $\mathrm{C}_{1-24}$ BAR at $25 \mu \mathrm{g} / \mathrm{ml}$ (D). Inhibition of $P$. gingivalis- $S$. gordonii interaction by $\mathrm{C}_{1-24} \mathrm{BAR}$ at $50 \mu \mathrm{g} / \mathrm{ml}$ concentration in a three species biofilm. 
TABLE 3. Percent Inhibition of $P$. gingivalis microcolony formation on $S$. gordonii substratum by BAR peptide and its analogs in three species biofilm

\begin{tabular}{|c|c|c|c|c|}
\hline & $\begin{array}{c}\text { Control: } \\
\text { Percentage } \\
\text { of } \\
\text { Inhibition }\end{array}$ & $\begin{array}{c}\text { Percent } \\
\text { Inhibition } \\
\text { at } \\
10 \mu \mathrm{g} / \mathrm{ml}\end{array}$ & $\begin{array}{c}\text { Percent } \\
\text { Inhibition } \\
\text { at } \\
25 \mu \mathrm{g} / \mathrm{ml}\end{array}$ & $\begin{array}{c}\text { Percent } \\
\text { Inhibition } \\
\text { at } \\
50 \mu \mathrm{g} / \mathrm{ml}\end{array}$ \\
\hline Parent BAR & $0 \%$ & $10.1 \%$ & $28 \%$ & $84.1 \%$ \\
\hline $\begin{array}{c}\mathrm{C}_{1-24} \mathrm{R}_{1182} \mathrm{I}_{1185} \\
\text { BAR }\end{array}$ & $0 \%$ & $\begin{array}{c}\text { No } \\
\text { reduction }\end{array}$ & $40 \%$ & $87.5 \%$ \\
\hline $\begin{array}{c}\mathrm{R}_{1182} \mathrm{I}_{1185} \\
\mathrm{BAR}\end{array}$ & $0 \%$ & $68 \%$ & $72.3 \%$ & $88 \%$ \\
\hline $\mathrm{C}_{1-24} \mathrm{BAR}$ & $0 \%$ & $\begin{array}{c}\text { Decrease in } \\
\text { S. gordonii } \\
\text { volume also } \\
\text { observed }\end{array}$ & $\begin{array}{c}\text { Decrease in } \\
\text { S. gordonii } \\
\text { volume also } \\
\text { observed }\end{array}$ & $\begin{array}{c}\text { Decrease in } \\
\text { S. gordonii } \\
\text { volume also } \\
\text { observed }\end{array}$ \\
\hline
\end{tabular}


TABLE 4. Percentage of reduction in $F$. nucleatum levels due to the inhibition of $P$. gingivalis- $S$. gordonii interaction by BAR peptide and its analogs in a three species complex biofilm.
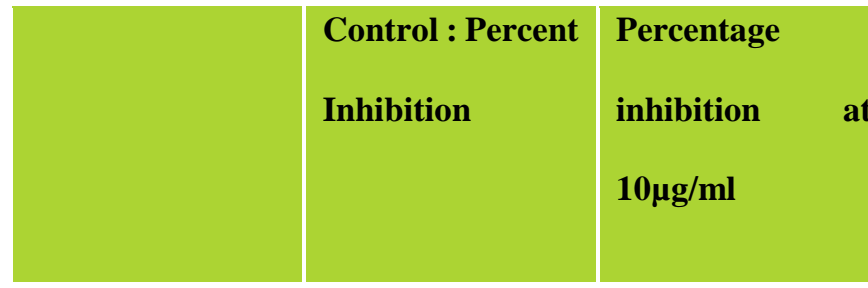

Percentage
inhibition at
$25 \mu \mathrm{g} / \mathrm{ml}$

Percentage

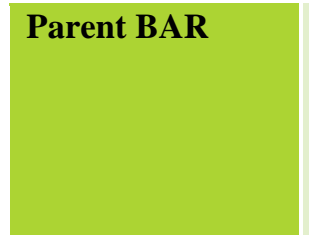

$0 \%$

$\begin{array}{llll}\text { C } & 1-24 & R_{1182} & I_{1185}\end{array}$

$0 \%$

No reduction

\section{BAR}

$\mathbf{R}_{1182}$ I1185 BAR $_{10}$

$0 \%$

\section{1 -24 BAR}

$0 \%$

$1.5 \%$

$63.5 \%$

$85.1 \%$

Reduction in $S$. Reduction in $S$. Reduction in $S$. gordonii volume gordonii volume gordonii volume also observed. also observed. also observed. 
The three species biofilm that was formed was much more complex when compared to dual species biofilm. Thick biofilms were observed in the three species biofilm. To determine if synergism between $P$. gingivalis and $F$. nucleatum was the reason for the complexity of the three species biofilm and the reason for reduction in $F$. nucleatum volume as $P$. gingivalis microcolonies were inhibited by the BAR peptide and its analogs, we formed $S$. gordonii and F. nucleatum biofilms as shown in Fig. 14. (A-B) and compared it with three species complex biofilm. But they were similar to the dual species biofilm in appearance though the dual species biofilms were formed by $S$. gordonii and $P$. gingivalis. This shows that there is a strong synergism between $P$. gingivalis and $F$. nucleatum which increased the complexity of the three species biofilm resulting in robust biofilms and in the absence of $P$. gingivalis the $S$. gordonii-F. nucleatum biofilm was not complex when compared to the three species biofilm. This agrees with the previous research done involving $P$. gingivalis and $F$. nucleatum supporting the fact that $P$. gingivalis and $F$. nucleatum have a strong synergistic effect ${ }^{46}$.

Though BAR peptide and its analogs potently inhibited three species biofilm at $50 \mu \mathrm{g} / \mathrm{ml}$ concentration, the structurally modified BAR peptide $\mathrm{R}_{1182} \mathrm{I}_{1185}$ BAR showed a comparatively significant inhibition of the three species biofilm at all the three concentrations $10 \mu \mathrm{g} / \mathrm{ml}, 25 \mu \mathrm{g} / \mathrm{ml}$ and $50 \mu \mathrm{g} / \mathrm{ml}$ when compared to BAR peptide, $\mathrm{C}_{1-24} \mathrm{R}_{1182}$ $\mathrm{I}_{1185}$ BAR and $\mathrm{C}_{1-24} \mathrm{BAR}$ (TABLE 3 ). 
Figure.14
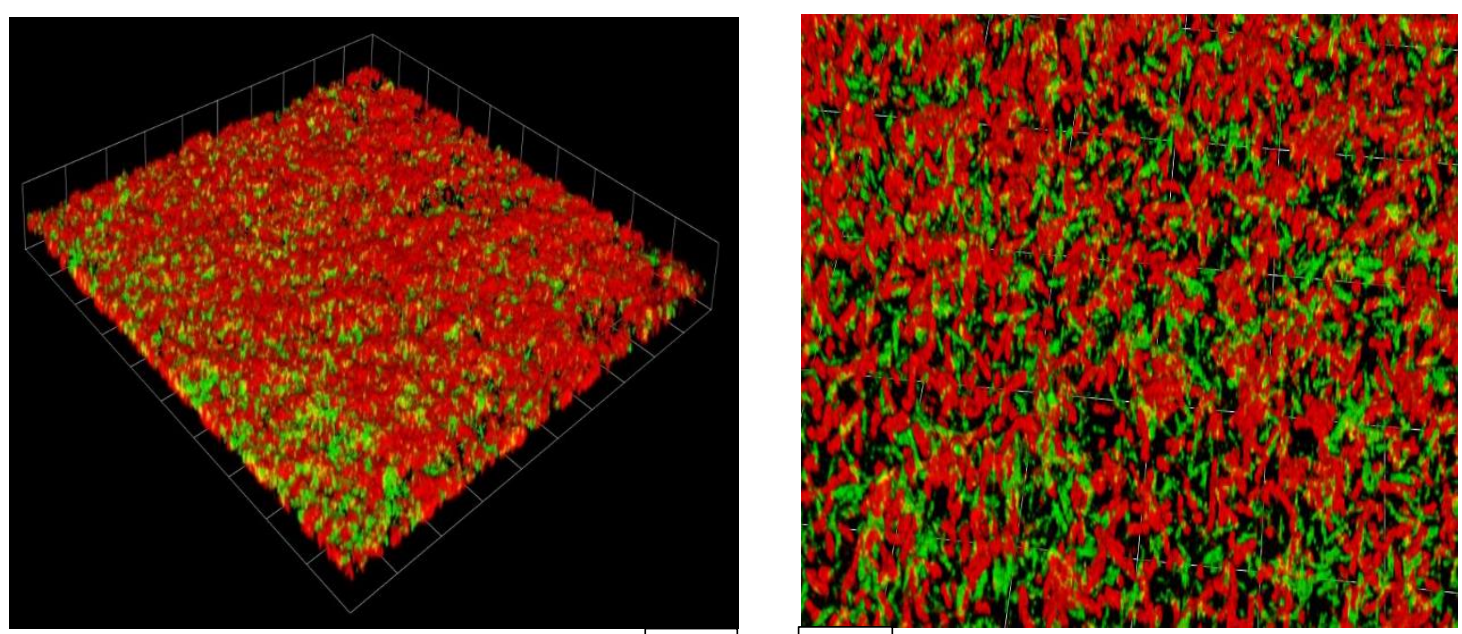

A

B

Figure. 14. (A) AND (B). Streptococcus gordonii (red- Hexidium iodide) Fusobacterium nucleatum (green- Carboxyfluorescein succinyl ester) dual species biofilm. 


\section{CHAPTER 5}

\section{DISCUSSION}

The periodontal pathogen $P$. gingivalis is a highly proteolytic, asaccharolytic gram negative anaerobe ${ }^{47}$. Its primary niche is the anaerobic environment of the sub- gingival dental plaque ${ }^{37}$. But the early plaque formation and initial colonization starts at the supra gingival surfaces ${ }^{37}$. In order to get established in the oral cavity, $P$. gingivalis has to survive the aerobic environment, should have sufficient nutritional sources and mainly it has to reach its primary niche where it can interact with other gram negative obligate and facultative anaerobes. To accomplish this $P$. gingivalis which is a secondary colonizer adheres to the primary colonizing bacteria at the supra-gingival surfaces.

Previous studies have shown that $S$. gordonii adheres to the periodontal pathogen $P$. gingivalis through the interaction of $P$. gingivalis minor fimbrial antigen Mfa1 with a specific region of the streptococcal SspB polypeptide(residues 1167 to 1193) designated BAR and that a synthetic peptide comprising the BAR sequence effectively inhibited the P. gingivalis $-S$. gordonii biofilms ${ }^{37}$. This synthetic peptide is termed as BAR peptide. Further investigations done on the BAR peptide provided structural information that was used to design structurally modified BAR peptides. Our current studies focused on testing the efficiency of these structurally modified BAR peptides in the inhibition of $P$. gingivalis- 
S. gordonii in a dual species biofilm when compared to the BAR peptide. Furthermore we also wanted to test the efficiency of the BAR peptide and its peptide analogs in inhibiting P. gingivalis-S. gordonii interaction in a three species complex biofilm and to determine if blocking the interaction alters the formation of three species biofilms.

Here we show that a BAR peptide analog $R_{1182} I_{1185}$ BAR synthesized using structural information from BAR functioned as a potent inhibitor of $P$. gingivalis adherence to $S$. gordonii and its subsequent formation of biofilms when compared to BAR peptide.

From our results in dual species biofilms, we calculated that the number of $P$. gingivalis microcolonies that formed on the streptococcal substrate reduced by $87 \%$ in the presence of approximately $10 \mu \mathrm{g}$ of peptide inhibitor per ml. This observation agrees with the previous research suggesting that electrostatic and hydrophobic interactions may contribute to Mfa1-SspB binding and that the SspB-Mfa1 interaction does not strictly depend on the specific amino acid occupying these positions in SspB but rather on the physical properties and characteristics of the amino acid residue. Our results showed that the BAR peptide and its analogs significantly inhibited $P$. gingivalis microcolony formation on S. gordonii substrate at $10 \mu \mathrm{g} / \mathrm{ml}$ in a dual species biofilm as shown in Fig. 5, Fig. 6, Table. 1 and Table. 2. The dose response of $R_{1182} I_{1185}$ BAR at $10 \mu \mathrm{g} / \mathrm{ml}$ concentration was statistically greater when compared to BAR peptide as shown in Fig. 5. The inhibitory activity of $\mathrm{C}_{1-24} \mathrm{R}_{1182} \mathrm{I}_{1185} \mathrm{BAR}$ was $7 \%$ less than the activity of BAR peptide at $10 \mu \mathrm{g} / \mathrm{ml}$ and the inhibitory activity of $\mathrm{C}_{1-24}$ BAR was equal to BAR peptide at $10 \mu \mathrm{g} / \mathrm{ml}$ as shown in Table 2 . 
To determine if the BAR peptide and its analogs inhibit $P$. gingivalis and $S$. gordonii interaction in a three species complex biofilm and also to determine if blocking S. gordoniiP. gingivalis interaction alters the formation of 3 species biofilm we tested BAR peptide and its analogs in three species complex biofilms as described in Materials and Methods.

Our results showed that BAR peptide and its analogs showed effective inhibition at $50 \mu \mathrm{g} / \mathrm{ml}$ whereas the inhibition at $10 \mu \mathrm{g} / \mathrm{ml}$ was minimal or negligible. This suggests that BAR peptide and its analogs showed less specific inhibitory activity in a three species biofilm when compared to dual species biofilm. This might be due to the fact that the complexity of three species biofilm was much higher compared to dual species biofilm. This may be because of the strong synergism present between $P$. gingivalis and $F$. nucleatum which increase the complexity of three species biofilm by several fold compared to dual species biofilm. Previous studies have shown that $P$. gingivalis can form a heterotypic community with $F$. nucleatum and S. gordonii ${ }^{48}$. These studies have also shown that a community lifestyle facilitates physiologic support to $P$. gingivalis and that $P$. gingivalis increased in biomass due to attachment and recruitment ${ }^{48}$. Previous studies have shown a synergistic effect on pathogenicity between $P$. gingivalis and $F$. nucleatum invitro and in a murine model ${ }^{46}$. Coaggregation between $F$. nucleatum and $P$. gingivalis is strong and it may have the capability to alter the expression of virulence factors in individual microorganisms ${ }^{46}$. Previous studies have shown that $P$. gingivalis enhanced the growth of $F$. nucleatum thus presenting a direct evidence of $P$. gingivalis exerting a synergistic effect on biofilm formation by $F$. nucleatum ${ }^{49}$. Our results agree with the previous studies mentioned above that an increase in the biomass resulting in an increase 
in complexity of the biofilm occurs when $P$. gingivalis and $F$. nucleatum coaggregate with each other.

Other interesting feature found in our experiments was that $F$. nucleatum also reduced as the $P$. gingivalis- $S$. gordonii interaction was inhibited in the three species biofilm. So as the volume of $P$. gingivalis reduced- the synergistic effect is automatically reduced which in turn might have led to the reduction in the complexity of the three species biofilm. These results suggest that $P$. gingivalis and $F$. nucleatum have strong synergism between them which agrees with the previous studies as mentioned above. These results also emphasize on the fact that $P$. gingivalis might be the key pathogen involved in the transformation of a commensal plaque to pathogenic form. This agrees with previous studies conducted on $P$. gingivalis in murine models ${ }^{50}$.

Our results show that when $P$. gingivalis and $S$. gordonii interaction is inhibited either by BAR peptide or its analogs a significant reduction in both $P$. gingivalis and $F$. nucleatum was observed inspite of the strong co-aggregation and synergism present between them. Infact the reduction in $P$. gingivalis microcolonies formation on $S$. gordonii substratum led to the fall of the whole community suggesting that $P$. gingivalis might be the key pathogen in dental plaque.

The significance of this study is that we showed that BAR peptide and its analogs efficiently reduced $P$. gingivalis adherence to $S$. gordonii which interaction is v. important for its initial colonization in the oral cavity and to reach its primary niche. This reduction of $P$. gingivalis either by BAR peptide or its analogs was observed even in the presence of 
F. nucleatum suggesting that BAR peptide and its analogs might represent potential therapeutic compounds that may prevent or limit periodontitis.

In closing, future directions for experimental work include to synthesize easily reproducible compounds in low cost and less time having the same potent inhibitory properties as that of BAR peptide and its analogs. To find the cause of reduction in $S$. gordonii in a three species biofilm by $\mathrm{C}_{1-24} \mathrm{BAR}$. 


\section{REFERENCES}

1. http://www.perio.org/consumer/cdc-study.htm (Accessed: $15^{\text {th }}$ November 2013)

2. Petersen PE, Bourgeois D, Ogawa H, Estupinan-Day S, Ndiaye C. The global burden of oral diseases and risks to oral health. Bulletin of the World Health Organization. 2005. 83:661-9.

3. Eke PI, Dye BA, Wei L, Thornton-Evans GO, Genco RJ; CDC Periodontal Disease Surveillance workgroup: James Beck, Gordon Douglass, Roy Page, Gary Slade, George W. Taylor. Prevalence of periodontitis in adults in the United States: 2009 and 2010 Journal of dental research. 2012. 91:914-20.

4. Jemin Kim and Salomon Amar. Periodontal disease and systemic conditions: a bidirectional relationship Odontology. 2006. 94:10-21.

5. Highfield J. Diagnosis and classification of periodontal disease. Australian dental journal. 2009. 54:S11-26

6. Lindhe J, Ranney R, Lamster I, et al. Consensus report: Chronic periodontitis. Annals of Periodontology 1999. 4:38.

7. http://microbewiki.kenyon.edu/index.php/Fusobacterium_nucleatum

8. Do T, Devine D, Marsh PD. Oral biofilms: molecular analysis, challenges, and future prospects in dental diagnostics. Clinical, Cosmetic and Investigational Dentistry 2013. 28:11-9

9. Jill S. Nield-Gehrig. Dental Plaque Biofilms. http://www.2ndchance.info/bonesNield-Gehrig2003.pdf (Accessed on $14^{\text {th }}$ October 2013) 
10. <a href="http://www.intechopen.com/books/gingival-diseases-their-aetiologyprevention-and-treatment/plaque-biofilm" $\quad$ title="Plaque $\quad$ Biofilm">Plaque Biofilm</a.

11. JoAnn R. Gurenlian. The Role of Dental Plaque Biofilm in Oral Health. 2012. Expires March 31st, 2015. http://www.cdeworld.com/courses/20009

12. Gibbons RJ, Hay DI. Human salivary acidic proline-rich proteins and statherin promote the attachment of Actinomyces viscosus LY7 to apatitic surfaces. Infection and immunity 1988. 56: 439-44

13. Saravanan Periasamy , Paul E. Kolenbrander. 2009. Journal of Bacteriology. 191: 6804-6811.

14. Costerton JW, Cheng KJ, Geesey GG, et al... Bacterial biofilms in nature and disease. Annual Review of Microbiology. 1987. 41: 435-464.

15. Gibbons RJ. Microbial ecology: adherent interactions which may affect microbial ecology in the mouth. Journal of Dental Research. 1984. 63: 378-385.

16. Whittaker CJ, Klier CM, Kolenbrander PE. Mechanisms of adhesion by oral bacteria. Annual Review of Microbiology. 1996. 50: 513-552.

17. Wirthlin MR, Armitage GC. Dental plaque and calculus: microbial biofilms and periodontal diseases. In book: Periodontics Medicine, Surgery, and Implants, Elsevier Mosby. 2004. 1:99-116

18. Marsh, P.D. Dental Plaque as a Microbial Biofilm. Caries Research 2004. 38:204-211

19. Socransky, S. S., and A. D. Haffajee. The bacterial etiology of destructive Periodontal disease: current concepts. Journal of Periodontology 1992. 63:322-331. 
20. Diaz, P. I., N. I. Chalmers, A. H. Rickard, C. Kong, C. L. Milburn, R. J Palmer, Jr., and P. E. Kolenbrander. Molecular characterization of subject-specific oral microflora during initial colonization of enamel. Applied and Environmental Microbiology 2006. 72:2837-2848

21. Li, J., E. J. Helmerhorst, C. W. Leone, R. F. Troxler, T. Yaskell, A. D. Haffajee, S. S. Socransky, and F. G. Oppenheim. Identification of early microbial colonizers in human dental biofilm. Journal of Applied Microbiology 2004. 97:1311-1318.

22. Moore, W. E., and L. V. Moore. 1994. The bacteria of periodontal diseases. Periodontology 2000. 5:66-77.

23. Saravanan Periasamy, Paul E. Kolenbrander. Mutualistic Biofilm Communities Develop with Porphyromonas gingivalis and Initial, Early, and Late Colonizers of Enamel. Journal of Bacteriology. 2009. 191(22): 6804-6811

24. David J. Bradshaw, Philip D. Marsh, G. Keith Watson, Clive Allison. Role of Fusobacterium nucleatum and Coaggregation in Anaerobe Survival in Planktonic and Biofilm Oral Microbial Communities during Aeration. 1998. Infection and Immunity. 66: 4729-4732

25. Lamont, R. J. \& Jenkinson, H. F. Subgingival colonization by Porphyromonas gingivalis. Oral Microbiology and Immunology. 2000. 15, 341-349.

26. Marsh, P. D. Host defenses and microbial homeostasis: role of microbial interactions. Journal of Dental Research. 1989. 68, 1567-1575.

27. Marsh, P. D. Microbial ecology of dental plaque and its significance in health and disease. Advances in Dental Research. 1994. 8,263-271. 
28. Kolenbrander, P. E., R. N. Andersen, and L. V. Holdeman. Coaggregation of oral Bacteroides species with other bacteria: central role in coaggregation bridges and competitions. Infection and Immunity. 1985. 48:741-746.

29. Xie, H., G. S. Cook, J. W. Costerton, G. Bruce, T. M. Rose, and R. J. Lamont. Intergeneric communication in dental plaque biofilms. Journal of Bacteriology. 2000. 182:7067-7069

30. Demuth, D. R., D. C. Irvine, J. W. Costerton, G. S. Cook, and R. J. Lamont. Discrete protein determinant directs the species-specific adherence of Porphyromonas gingivalis to oral streptococci. Infection and Immunity. 2001. 69:5736-5741.

31. Kolenbrander, P. E., and R. N. Andersen. Inhibition of coaggregation between Fusobacterium nucleatum and Porphyromonas (Bacteroides) gingivalis by lactose and related sugars. Infection and Immunity. 1989. 57:3204-3209

32. http://microbewiki.kenyon.edu/index.php/Fusobacterium_nucleatum.

33. Satyendra Satyanarayana and Robert $L$ White. Fusobacterial Infections. The Dalhousie Medical Journal. 1999. May.

34. Saito Y, Fujii R, Nakagawa KI, Kuramitsu HK, Okuda K, Ishihara K. Stimulation of Fusobacterium nucleatum biofilm formation by Porphyromonas gingivalis. Oral Microbiology and Immunology. 2008. 23: 1-6

35. Noguchi N, Noiri Y, Narimatsu M, Ebisu S. Identification and localization of extra radicular biofilm forming bacteria associated with refractory endodontic pathogens. Applied and Environmental Microbiology. 2005: 71: 8738-8743. 
36. Polak D, Wilensky A, Shapira L, Halabi A, Goldstein D, Weiss EI, Houri-Haddad Y. Mouse model of experimental periodontitis induced by Porphyromonas gingivalis/Fusobacterium nucleatum infection: bone loss and host response. Journal of Clinical Periodontology. 2009. 36:406-10

37. Daep, C. A., D. M. James, R. J. Lamont, and D. R. Demuth. Structural characterization of peptide-mediated inhibition of Porphyromonas gingivalis biofilm formation. Infection and Immunity. 2006. 74:5756-5762.

38. Brooks, W., D. R. Demuth, S. Gil, and R. J. Lamont. Identification of a Streptococcus gordonii $\mathrm{SspB}$ domain that mediates adhesion to Porphyromonas gingivalis. Infection and Immunity. 1997. 65:3753-3758.

39. Shanitzki B, Hurwitz D, Smorodinsky N, Ganeshkumar N, Weiss EI. Identification of a Fusobacterium nucleatum PK1594 galactose-binding adhesion which mediates coaggregation with periodontopathogenic bacteria and hemagglutination. Infection and Immunity. 1997. 65: 5231-7.

40. Hamada, N., H. T. Sojar, M.-I. Cho, and R. J. Genco. Isolation and characterization of a minor fimbria from Porphyromonas gingivalis. Infection and Immunity. 1996. 64:4788-4794.

41. Ogawa, T., K. Yasuda, K. Yamada, H. Mori, K. Ochiai, and M. Hasegawa. Immunochemical characterisation and epitope mapping of a novel fimbrial protein (P.g-II fimbria) of Porphyromonas gingivalis. FEMS Immunology and Medical Microbiology 1995. 11:247-255.

42. Lamont, R. J., A. El-Sabaeny, Y. Park, G. S. Cook, J. W. Costerton, and D. R. Demuth. Role of Streptococcus gordonii $\mathrm{SspB}$ protein in the development of 
Porphyromonas gingivalis biofilms on streptococcal substrates. Microbiology. 2002. 148:1627-1636.

43. Daep, C. A., R. J. Lamont, and D. R. Demuth. Interaction of Porphyromonas gingivalis with oral streptococci requires a motif that resembles the eukaryotic nuclear receptor box protein-protein interaction domain. Infection and Immunity. 2008. 76:3273-3280.

44. Darimont, B. D., R. L. Wagner, J. W. Apriletti, M. R. Stallcup, P. J. Kushner, J. D. Baxter, R. J. Fletterick, and K. R. Yamamoto. Structure and specificity of nuclear receptor-coactivator interactions. Genes and Development. 1998. 12:3343-3356.

45. http://www.sciencedaily.com/articles/c/confocal_laser_scanning_microscopy.htm

46. Feuille F, Ebersole JL, Kesavulu L, Stepfen, MJ, Holt, SC. Mixed infection with Porphyromonas gingivalis and Fusobacterium nucleatum in a murine lesion model: potential synergistic effects on virulence. Infection and Immunity 1996: 64: 2095-2100.

47. Lamont, R.J., HOWARD F. Jenkinson. Oral Microbiology at a glance. 2010. 47

48. Masae Kuboniwa, Erik L Hendrickson, Qiangwei Xia, Tiansong Wang, Hua Xie,Murray Hackett, Richard J Lamont. Proteomics of Porphyromonas gingivalis within a model oral microbial community. BMC Microbiology. 2009 May 19; 9:98. Doi: 10. 1186/1471-2180-9-98.

49. Y. Saito, R. Fujii, K. -I. Nakagawa, H. K. Kuramitsu, K. Okuda. K. Ishihara. Stimulation of Fusobacterium nucleatum biofilm formation by Porphyromonas gingivalis. Oral Microbiology and Immunology. 2008. 23(1): 1-6

50. Darveau RP, Hajishengallis G, Curtis MA. Porphyromonas gingivalis as a potential community activist for disease. Journal of Dental Research. 2012. 91: 816-20. 


\section{APPENDIX I ABBREVIATIONS \\ PBS- Phosphate buffer saline \\ PFA- Paraformaldehyde \\ CLSM- Confocal laser scanning microscopy}




\section{CURRICULUM VITAE}

NAME: $\quad$ Naga Srinija Gummadi

ADDRESS: 1419, NE Lockheart Ln, Hillsboro OR 97124

Email: n0gumm02@louisville.edu

EDUCATION \& TRAINING:

UNIVERSITY OF LOUISVILLE M.S 12/2013 Oral Biology SCHOOL OF DENTISTRY

Dr. N. T. R. UNIVERSITY OF B.D.S 12/2009 Dentistry

HEALTH SCIENCES

A.P, INDIA

SERVICE:

- Served in several Dental camps as a Dentist.

- Served in Flood relief Medical and Dental camps in Amudala lanka, Krishna District, A.P, India.

- Dental camps in Duggirala, A.P, India.

- Created a small scale model of a Health authority and formulated a program called "VELUGU" along with some of Medical school friends and through this we served the agricultural community in villages which had little, if any access to primary health. We also donated free samples of vitamin supplements, painkiller 
antacids, iron supplements and oral rehydration therapy sachets collected from my

\& my friend's university hospitals.

- Conducted Dental Health Education classes on the weekends. As a part of it, I made them aware of their responsibilities and of the steps they must take to receive the full length benefits of prevention at all levels. Focused on prevention of disease and attainment of positive health habits and putting into practice, educated hundreds of people regarding oral health care in Vijayawada and Guntur, A.P, India

\section{RESEARCH:}

- Graduate Research at the University of Louisville 2011- Present

- Thesis: Peptide mediated inhibition of Porphyromonas gingivalis dual and three species biofilms

- Project Presented at Fall2011, Fall2012 and Fall2013 Research Louisville

- University of Louisville Summer Research Program 2011,2012 and 2013

- Manuscript in progress for submission

\section{WORK HISTORY:}

Chakrapani Multi Speciality Dental Hospital

Dentist

Happy Dent Dental Hospital

Dentist
Guntur, A.P, India

2008-2010

Hyderabad

2010 